\title{
Waste Glass Utilization in Cement-Based Materials for Sustainable Construction: A Review
}

\author{
Di Qin ${ }^{1}$, Yidan $\mathrm{Hu}^{1}$ and Xuemei $\mathrm{Li}^{2, *}$ \\ 1 Changchun Institute of Technology, Changchun 130021, China; qindi@ccit.edu.cn (D.Q.); \\ huyidan@ccit.edu.cn (Y.H.) \\ 2 Changchun Sci-Tech University, Changchun 130600, China \\ * Correspondence: 100464@cstu.edu.cn
}

Citation: Qin, D.; Hu, Y.; Li, X. Waste Glass Utilization in Cement-Based

Materials for Sustainable Construction: A Review. Crystals 2021, 11, 710. https://doi.org/ $10.3390 /$ cryst11060710

Academic Editors: Piotr Smarzewski and Adam Stolarski

Received: 8 June 2021

Accepted: 17 June 2021

Published: 21 June 2021

Publisher's Note: MDPI stays neutral with regard to jurisdictional claims in published maps and institutional affiliations.

Copyright: (c) 2021 by the authors. Licensee MDPI, Basel, Switzerland. This article is an open access article distributed under the terms and conditions of the Creative Commons Attribution (CC BY) license (https:// creativecommons.org/licenses/by/ $4.0 /)$.
Abstract: The construction industry has a significant environmental impact, contributing considerably to $\mathrm{CO}_{2}$ emissions, natural resource depletion, and energy consumption. The construction industry is currently trending towards using alternative construction materials in place of natural materials and cement, thereby reducing the environmental impact and promoting sustainability. Two approaches have been used in this review: scientometric analysis and a comprehensive manual review on the waste glass (WG) utilization in cement-based materials (CBMs) as a sustainable approach. Scientometric analysis is conducted to find out the current research trend from available bibliometric data and to identify the relevant publication fields, sources with the most publications, the most frequently used keywords, the most cited articles and authors, and the countries that have made the most significant contribution to the field of WG utilization in CBMs. The effect of WG on the mechanical properties of CBMs was found to be inconsistent in the literature. The inconsistent effects of WG impede its acceptance in the construction sector. This study intends to shed light on the arguments and tries to explain the opposing perspectives. This article summarizes the findings of various research groups and recommends new viewpoints based on the assessment of fundamental processes. The effect of utilizing WG on fresh and hardened properties of CBMs, including workability, compressive strength, split-tensile strength, and flexural strength, are reviewed. Furthermore, the microstructure and durability of composites containing WG are investigated. Different limitations associated with WG use in CBMs and their possible solution are reported. This study will assist researchers in identifying gaps in the present research. Additionally, the scientometric review will enable researchers from diverse regions to exchange novel ideas and technologies, collaborate on research, and form joint ventures.

Keywords: cement-based materials; waste glass; sustainable construction; mechanical properties; durability

\section{Introduction}

Sustainability trends have accelerated recently as a result of resource constraints, resulting in an increased number of emerging issues from managerial, strategic, and operational perspectives. Additionally, the construction sector significantly contributes to society's requirements by improving people's quality of life [1-3]. Despite this, this industry generates between 45 and $65 \%$ of waste disposed of in landfills, accounting for 35\% of global $\mathrm{CO}_{2}$ emissions. Additionally, the construction industry and its related activities generate substantial amounts of harmful emissions, accounting for nearly $30 \%$ of global greenhouse gas emissions resulting from construction operations, with transportation and processing of construction materials accounting for $18 \%$ of these emissions [4]. The value of sustainability research in the field of civil construction is self-evident. In this regard, firms are increasingly aware that ensuring a competitive advantage is contingent on more than just client satisfaction based on low costs and the quality of the product or service provided. Clients expect businesses to be ethical, environmentally conscious, and socially 
responsible [5]. As a result, sustainability in construction must be seriously considered. Researchers have concentrated on a variety of factors in order to achieve construction sustainability. One of them is the utilization of waste materials in construction materials.

Several processes, including mining, manufacturing, agricultural production, electricity generation, iron and steel metallurgy, and electronic goods, generate massive amounts of solid waste. Many hazardous solid wastes are flammable, chemically reactive, incendiary, corrosive, and infectious, and their discharge and disposal have resulted in large financial losses [6,7]. As a result, solid waste recycling or reuse in construction materials would be preferable [8]. Cement-based materials (CBMs) are extensively used construction materials [9-12]. Researchers have used various approaches to enhance the performance of CBMs [13-16]. Waste materials can be used in concrete as an aggregate substitute [17-22], as fibers for reinforcement [23-28], as well as a cement substitute [29-35] to improve CBMs' performance. As a result of the reduced cement consumption, natural resources can be conserved, and $\mathrm{CO}_{2}$ emissions can be reduced. Furthermore, it has been discovered that incorporating waste materials into CBMs improves their mechanical performance [36-38]. Each year, tens of millions of tons of waste glass (WG) are produced in the United States [39], with a huge quantity of WG being disposed of in landfills. Although many cities are producing more WG at a growing rate, landfill space is becoming scarce, particularly in major cities. Glass is chemically stable as compared to certain forms of solid waste, such as plastic and wood. Glass that has been buried in soil for a long time is non-biodegradable [40]. Furthermore, certain glass, for example, cathode ray tube (CRT) glass, holds toxic elements such as mercury, cadmium, lead, and beryllium, polluting subsurface soil and water [41]. China produces CRT glass at a rate of more than 43 million tons per year [42], posing a major environmental threat and endangering public health. Glass production requires a considerable amount of energy as silica must be melted at an elevated temperature for hours [43]. For container glass, the temperature is kept at $1500{ }^{\circ} \mathrm{C}$ for 24 and $72 \mathrm{~h}$ for plate glass [44]. Producing $1 \mathrm{~kg}$ of plate glass utilizes approximately $17 \mathrm{MJ}$ (mega-joule) of fossil fuel energy and emits approximately $0.6 \mathrm{~kg}$ of $\mathrm{CO}_{2}$ [45]. In Europe, annual energy consumption for glass manufacturing exceeds $350 \mathrm{PJ}$ (peta-joule), accounting for approximately $20 \%$ of overall industrial energy utilization [45]. Thus, recycling WG effectively is generating increasing interest worldwide. Recycling glass for use in the manufacture of glass products is a popular method of reusing WG. However, recycling is a complicated process. To produce glass plates and containers, WG ought to be cleaned, sorted, and melted [46]. Another way to recycle WG is to use it to make construction materials. WG can be crushed and mixed with cement and aggregates in CBMs to partially replace cement/aggregates [21,47-51]. The use of WG in CBMs has several benefits. First, the WG utilized in CBMs does not need to be melted, so minimizing the energy requirement. Second, WG management is significantly simplified. For example, glass cleaning and sorting are not required. Third, WG consumption will be high due to the extensive use of CBMs in construction. Fourth, toxic elements in glass can be locked and solidified within CBMs. Present research indicates that recycling WG in CBMs is a better approach [47,48]. Thus, the use of WG in construction materials as an aggregate replacement will contribute to save natural resources and solve waste management problems. Its use as a cement replacement will help to reduce the cement demand and ultimately decrease $\mathrm{CO}_{2}$ emission.

As a result, there is a need to investigate sustainability in construction, which has been discussed in this paper. Manual reviews are insufficient for building a deep and consistent relationship between different literature sections. Scientific mapping and network visualization of bibliographic coupling, co-citations, and co-occurrence are currently among the most difficult parts of modern research. A scientometric review can deal with large amounts of data without adding to the complexity of responding to the fundamental limitations of earlier manual evaluations. To solve the fundamental drawbacks of traditional reviews, scientometric analysis is used in conjunction with traditional reviews in this study. More specifically, a thorough examination of the keywords co-occurrence, co-authorship by researchers, bibliographic coupling of sources, articles, and countries actively contributing 
to the subject of the utilization of WG in concrete for sustainable construction is conducted. The effect of WG on the mechanical properties (MPs), microstructure, and durability of CBMs are reviewed. Various limitations associated with WG utilization are identified, and their possible solution is detailed. In the current study, scientometric analysis is used in conjunction with an in-depth discussion to achieve the following objectives: (1) To identify the most relevant publishing field, publication sources, most frequently used keywords, most cited authors and works, and nations with the greatest influence in the field of WG utilization for sustainability in construction. (2) To examine the current level of research and its focus on a variety of elements throughout the last two decades. (3) To identify research gaps so that future research can be directed in the proper direction.

\section{Research Significance}

In recent decades, a substantial study has been done to explore the elements that contribute to sustainability in construction, and some useful results have been reached. Review studies were also conducted; however, these were primarily manual reviews. This study is based on scientometric analysis, as well as an in-depth discussion on WG utilization in CBMs as a sustainable approach. The reason for selecting WG from the various waste materials is because it is non-biodegradable and contains toxic chemicals that have a greater detrimental impact on the environment if disposed of in landfills. Researchers from various locations may benefit from the graphical depiction based on a scientometric evaluation in forging research alliances, forming joint ventures, and sharing breakthrough technologies and ideas as a result of this research. Furthermore, the advantages associated with WG utilization in construction are described. Specifically, the impact of WG on the mechanical performance of CBMs and its sustainability aspects are reviewed. Different restrictions related to the use of WG are also discussed, as well as possible remedies. Finally, possible future studies are recommended.

\section{Methodology}

This study employed two approaches: a scientometric analysis review [52-55] and an in-depth discussion on WG utilization in construction materials. The primary reason for instituting a scientometric review method is that subjective analyses of civil engineering studies by researchers have been shown to be prone to error. Scientometrics, by itself, provides a more rational and less skewed outcome, as it is not biased by any individual's perspective [56-58]. This study examines and articulates findings spanning two decades. Maps and connections between bibliometric data are used to quantify research progress in this report, resulting in a quantitative assessment.

Numerous publications have been written in the area under study, and it is critical to locate the most accurate database. According to Aghaei et al. [59], the two most effective, comprehensive, and objective databases for conducting literature searches are Web of Science and Scopus. Scopus has a broader coverage and more up-to-date bibliometric data than Web of Science [59-61]. Scopus was used to compile the bibliometric data for the current analysis on the utilization of WG for sustainable construction. The searched keyword in Scopus was "waste glass in concrete", which resulted in 1488 documents. Options for data refinement were used to weed out irrelevant publications. From the "document type", only "article" and "review" were selected. The "source type" field was kept to "journal", while the "language" field was "English". The "publication year" was limited from 2001 to 2021. The "subject area" was kept "Engineering, Material Science, and Environmental Science". After applying these limiting filters, the resulting documents were 737. Researchers from a variety of fields have previously conducted research using similar methods [62-64]. Scientometric reviews make use of science visualization, a technique developed by scholars for analyzing bibliometric data for a variety of purposes [65]. It describes the difficulties researchers face when conducting manual reviews and also establishes a connection between sources, keywords, authors, articles, and countries within a particular research area [66]. Scopus data were saved in the Comma Separated Values (CSV) format for subsequent 
analysis with an appropriate software tool. The science mapping and visualization were created using the software tool VOSviewer (version: 1.6.16). VOSviewer is a freely available visualization application that is widely used in a variety of fields and comes highly recommended in the literature [67-71]. Hence, the VOSviewer was used to accomplish the current study's objectives. The analysis was conducted in VOSviewer, with the "type of data" set to "create a map from bibliographic data" and the "data source" set to "read data from bibliographic database files". The CSV file downloaded from Scopus was imported into VOSviewer and analyzed in a few simple steps while ensuring data consistency and reliability. As part of the science mapping review, the sources of documents, keyword cooccurrence, citation network, co-authorship, articles, bibliometric overlapping, and country contributions were analyzed. Additionally, the cumulative number of citations to articles was tallied. Additionally, the connections between authors, publications, and countries were charted. Maps were used to visualize various parameters, their relationships, and co-occurrence, while tables were used to summarize their quantitative values. Additionally, the keywords were thoroughly reviewed and summarized in the discussion section in order to develop the major research themes. The sequence of the scientometric analysis is depicted in Figure 1.

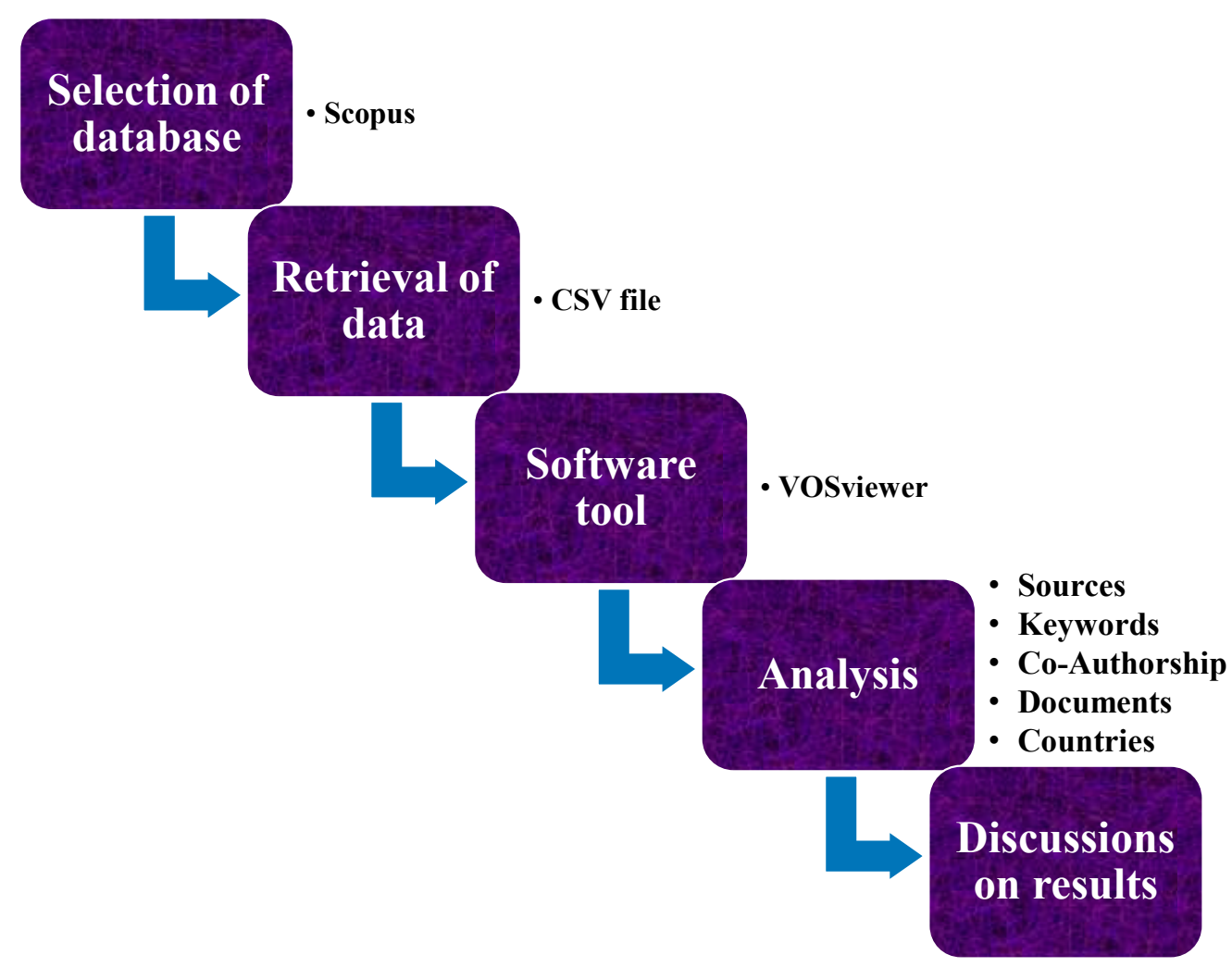

Figure 1. Sequence of scientometric analysis. CSV: comma separated values.

\section{Results and Discussion on Scientometric Analysis}

\subsection{Subject Area and Annual Publication Pattern of Articles}

The Scopus analyzer was used to search the Scopus database in order to determine the most significant research areas. The analysis revealed that the top three fields based on the number of documents were determined to be Engineering, Materials Science, and Environmental Science, containing $34.7 \%, 21.9 \%$, and $16.0 \%$ of the total documents, respectively, as illustrated in Figure 2. These fields account for around $72.6 \%$ of the total number of documents searched in the Scopus database. Both journal articles and review articles were compared for the overall documents. Journal articles contributed $90.9 \%$, and review articles contributed $9.1 \%$, respectively. Figure 3 depicts the annual publication pattern in the current study field from 2001 to 2021. A gradual increase in the number of publications 
on the utilization of WG in concrete has been observed up to 2016. However, a remarkable increase was observed in the last 5 years. It is fascinating to discover that scholars are now focusing their studies on sustainable construction methods.

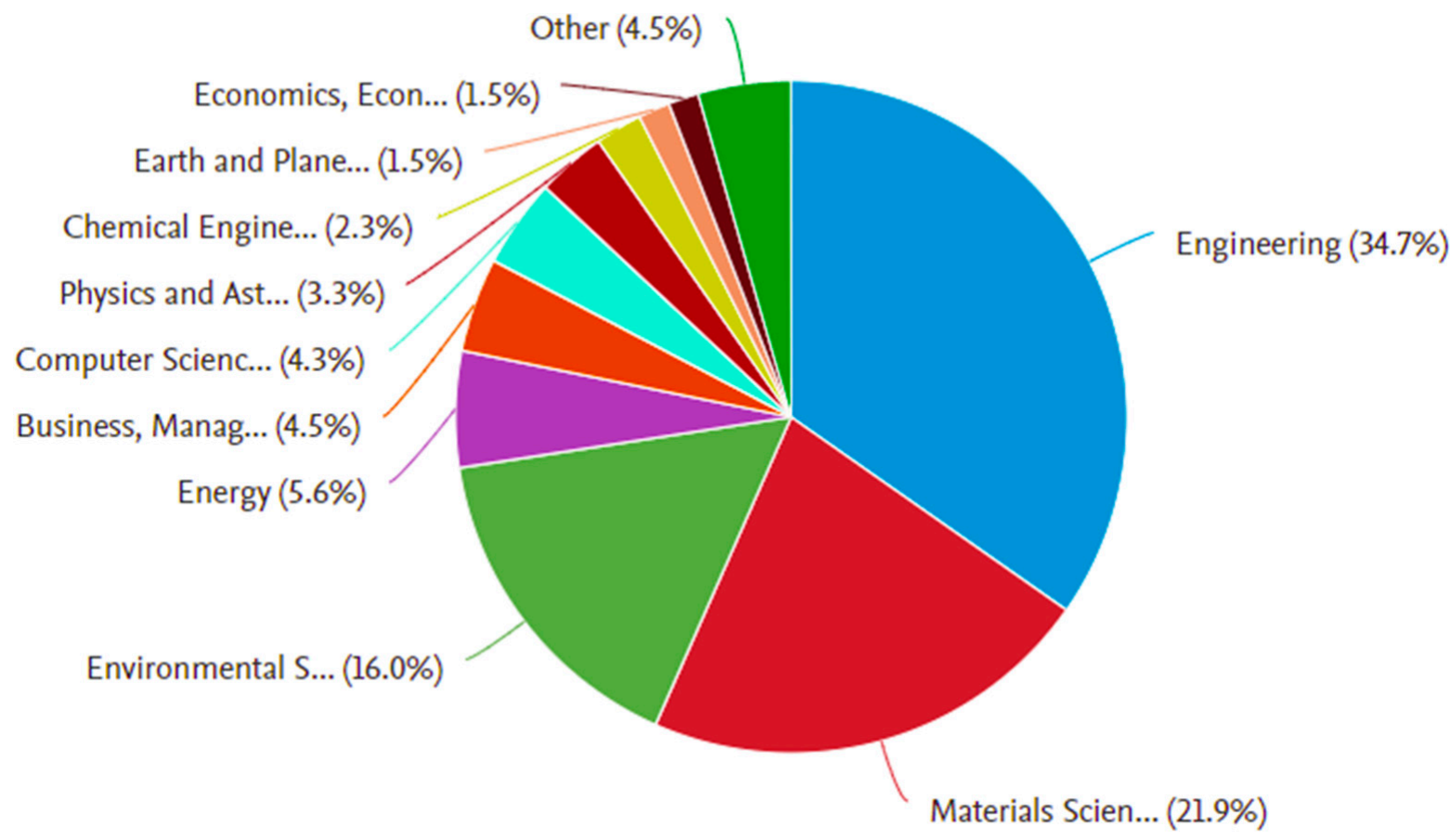

Figure 2. Subject area of articles.

Documents by year

150

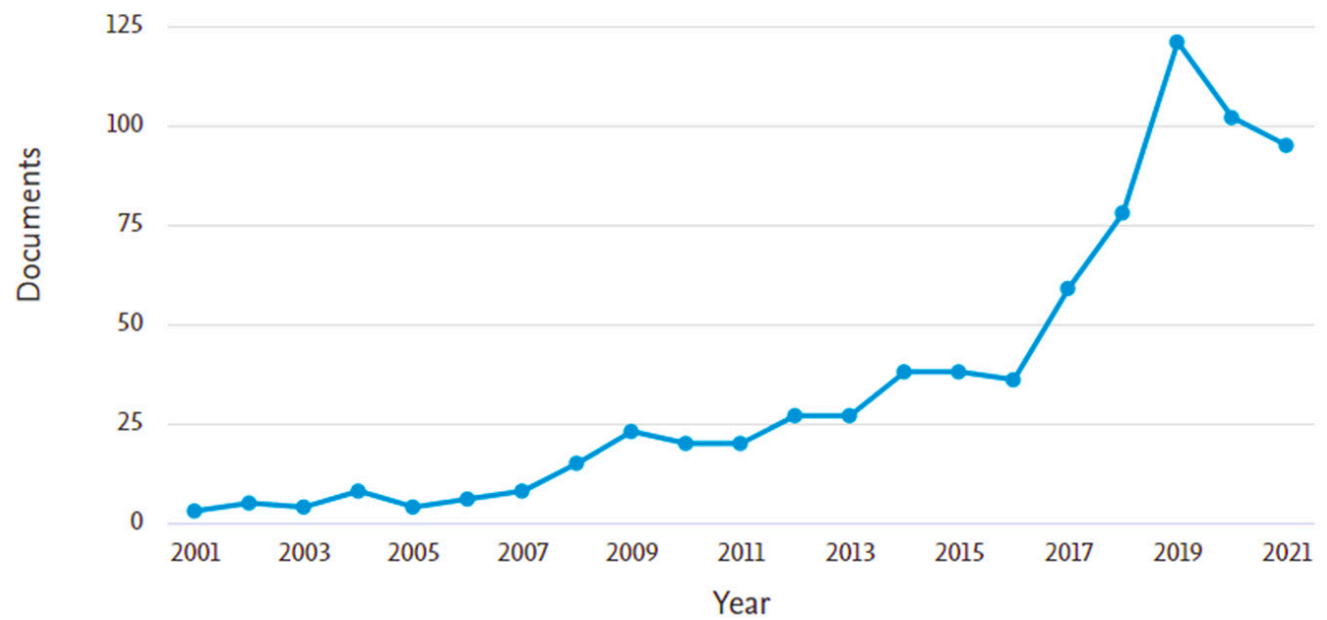

Figure 3. Annual publication pattern.

\subsection{Sources Mapping}

Mapping sources enables the analysis of development and innovation to be visualized. These sources make data available within the confines of predefined, unique constraints. By initializing the mapping of research origins, it is possible to apply the research pattern sequentially in the analysis area. This analysis was conducted in VOS viewer using Scopus bibliometric data. The "type of analysis" was selected to be "bibliographic coupling," and the "unit of analysis" was selected to be "sources". A source's minimum document 
count was set at 10, and 10 of the 256 sources met this criterion. Table 1 lists the leading sources/journals that publish at least 10 documents containing data on WG in concrete for sustainable development, along with their citations and total link strength. Based on the number of documents, the top 3 journals are construction and building materials, the journal of cleaner production, and the international journal of civil engineering and technology, containing 112, 56, and 25 documents, respectively. The highest citations are of construction and building materials (3989), followed by cement and concrete research (1935) and journal of cleaner production (1878). Figure 4 illustrates the annual publication trend of sources and their scientific mapping. This data was gathered as part of the process of establishing a network of research sources. It is worth noting here that this type of research would lay the groundwork for upcoming scientometric reviews in the current study field. Additionally, previous manual reviews lacked sufficient detail regarding science mapping. Figure 4a depicts the yearly publication trend of the top journals. The contribution of resources, recycling and conservation is from 2002. While the contribution of construction and building materials, journal of cleaner production, and materials is from 2007, 2009, and 2016, respectively, in the current study field. It can be seen that up to 2016, the number of publications was insignificant, while an abrupt hike in the last 5 years was observed especially for construction and building materials. The network visualization of journals containing at least 10 documents has been displayed in Figure $4 \mathrm{~b}$. The size of the frame in the figure corresponds to the journal's contribution in terms of citation and documents count; a larger frame size indicates a higher contribution. For example, construction and building materials has a bigger frame size, indicating that this journal has the greatest influence in the current study area relative to the other. Additionally, frames (sources) with identical colors display clusters of related frames developed through VOSviewer analysis. For instance, the red color indicates a cluster containing construction and building materials, journal of cleaner production, materials, journal of building engineering, and applied sciences (Switzerland). Clusters are formed based on the scope of research outlets or their co-citations. [72]. The number of co-citations in the articles in the current study area is indicated by the connection links between the research sources. Additionally, the link strength indicates the number of mutually cited references between two journals. For instance, the journal of cleaner production (total link strength: 9941) contained the greatest number of references to other research sources. Closely spaced frames (sources) in a cluster have stronger connections than those that are further apart. For example, the construction and building materials is more connected with cement and concrete composites than it is with other sources.

Table 1. Documents sources.

\begin{tabular}{ccccc}
\hline S/N & Source & Documents & Citations & $\begin{array}{c}\text { Total Link } \\
\text { Strength }\end{array}$ \\
\hline 1 & Construction and building materials & 112 & 3989 & 9941 \\
2 & Journal of cleaner production & 56 & 1878 & 5526 \\
3 & International journal of civil engineering & 25 & 70 & 437 \\
4 & and technology & 23 & 163 & 2785 \\
5 & Materials & 21 & 1770 & 1915 \\
6 & Resources, conservation and recycling & 20 & 260 & 3931 \\
7 & Journal of building engineering & 18 & 1792 & 1290 \\
8 & Waste management & 13 & 1261 & 2580 \\
9 & Cement and concrete composites & 10 & 35 & 1474 \\
10 & Applied sciences (switzerland) & 10 & 1935 & 513 \\
\hline
\end{tabular}




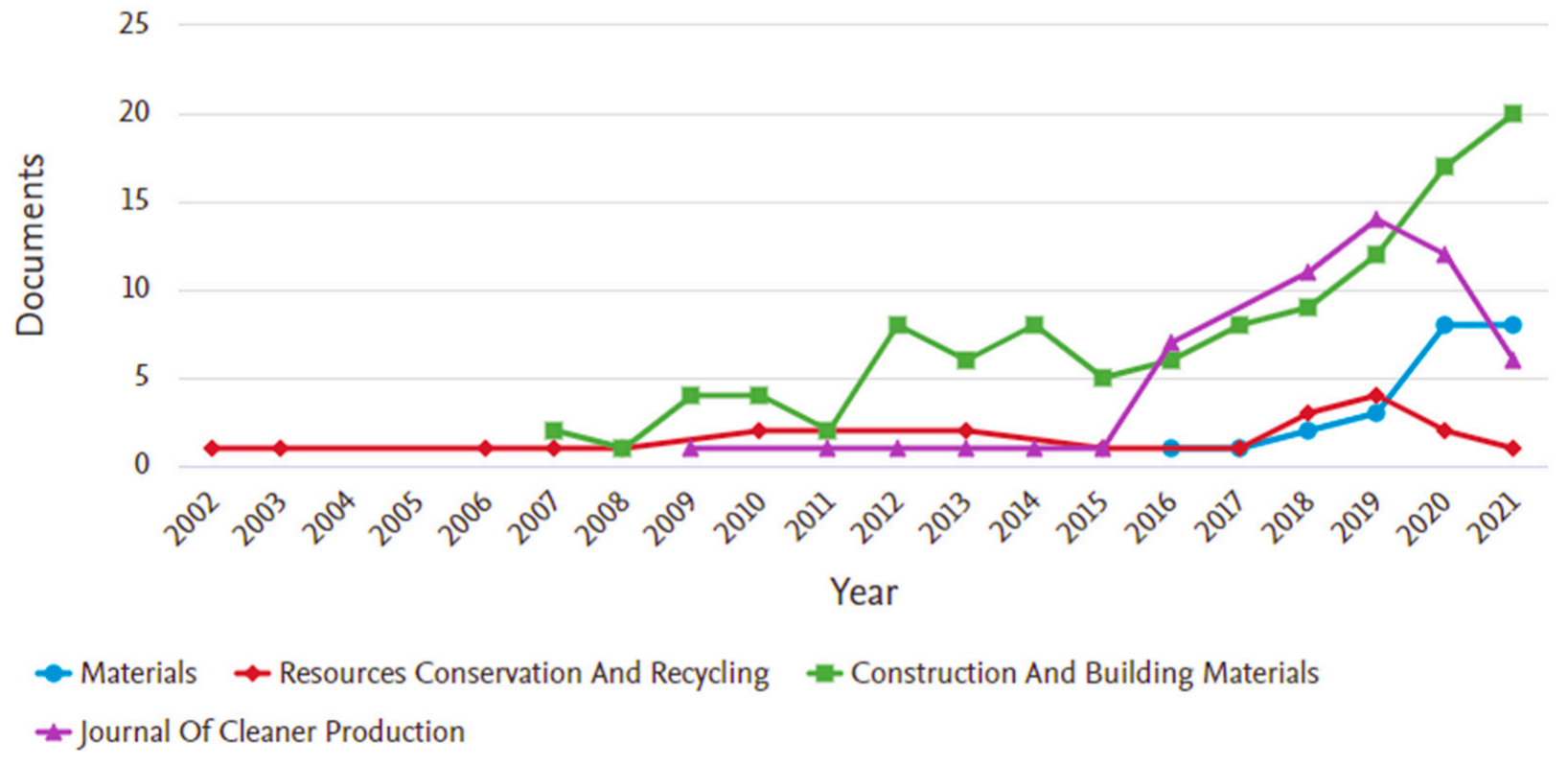

(a)



(b)

Figure 4. Sources of research articles: (a) yearly publication trend; (b) network visualization.

\subsection{Keywords Mapping}

Keywords are essential research materials because they identify and represent the research domain's fundamental field [73]. For that analysis, the "type of analysis" was chosen as "co-occurrence" and "unit of analysis" as "all keywords". The minimum number of occurrence of a keyword was kept to 20 . These constraints indicated that only 
100 keywords from 5576 satisfied the criteria. Table 2 lists the top 20 keywords having the most occurrence in the research articles used in the present study field. According to the researcher's study, the most commonly occurring keywords include glass, compressive strength, concretes, recycling, and concrete, making the top 5 mostly occurred keywords. Figure 5 illustrates the co-occurrence of keywords networks, their visualization, their connections to one another, and the density associated with their correlation frequency. The size of the keyword node in Figure 5a indicates its frequency, whereas its location indicates its co-occurrence in publications. Additionally, the visualization demonstrates that the aforementioned keywords have bigger nodes than the others, indicating that these are the most important keywords in the study of WG utilization in concrete for sustainable construction. Clusters of keywords have been colored differently in the network to indicate their co-occurrence in various publications. A total of five clusters were observed, represented by green, red, blue, yellow, and purple. For example, a cluster represented by green color contains glass, silica, cements, durability, silica fume, cement replacement, concrete mixtures, etc. As illustrated in Figure 5 b, the density concentration of keywords is denoted by distinct colors. Red, yellow, green, and blue are the colors in ascending order of density. For example, glass, compressive strength, and concretes have red marks in the density visualization, indicating a higher density. This finding will aid writers in the future when selecting keywords to make it easier to locate published data in a particular domain. Figure 6 illustrates the connections of glass (Figure 6a), waste management (Figure 6b), and recycling (Figure 6c) with other keywords. The connection network demonstrates that glass and recycling have a sizeable impact on waste management. Thus, recycling WG would reduce the burden from waste management authorities.

Table 2. Top 20 most occurred keywords.

\begin{tabular}{cccc}
\hline S/N & Keyword & Occurrences & Total Link Strength \\
\hline 1 & Glass & 407 & 3435 \\
2 & Compressive strength & 257 & 2102 \\
3 & Concretes & 232 & 2028 \\
4 & Recycling & 225 & 1938 \\
5 & Concrete & 172 & 1374 \\
6 & Aggregates & 171 & 1576 \\
7 & Concrete aggregates & 145 & 1298 \\
8 & Waste glass & 111 & 925 \\
9 & Cements & 110 & 984 \\
10 & Fly ash & 99 & 869 \\
11 & Durability & 96 & 867 \\
12 & Mechanical properties & 93 & 758 \\
13 & Silica & 91 & 913 \\
14 & Waste management & 87 & 726 \\
15 & Mortar & 75 & 707 \\
16 & Glass powder & 73 & 538 \\
17 & Portland cement & 73 & 700 \\
18 & Water absorption & 72 & 667 \\
19 & Slags & 68 & 666 \\
20 & Tensile strength & 67 & 638 \\
\hline
\end{tabular}




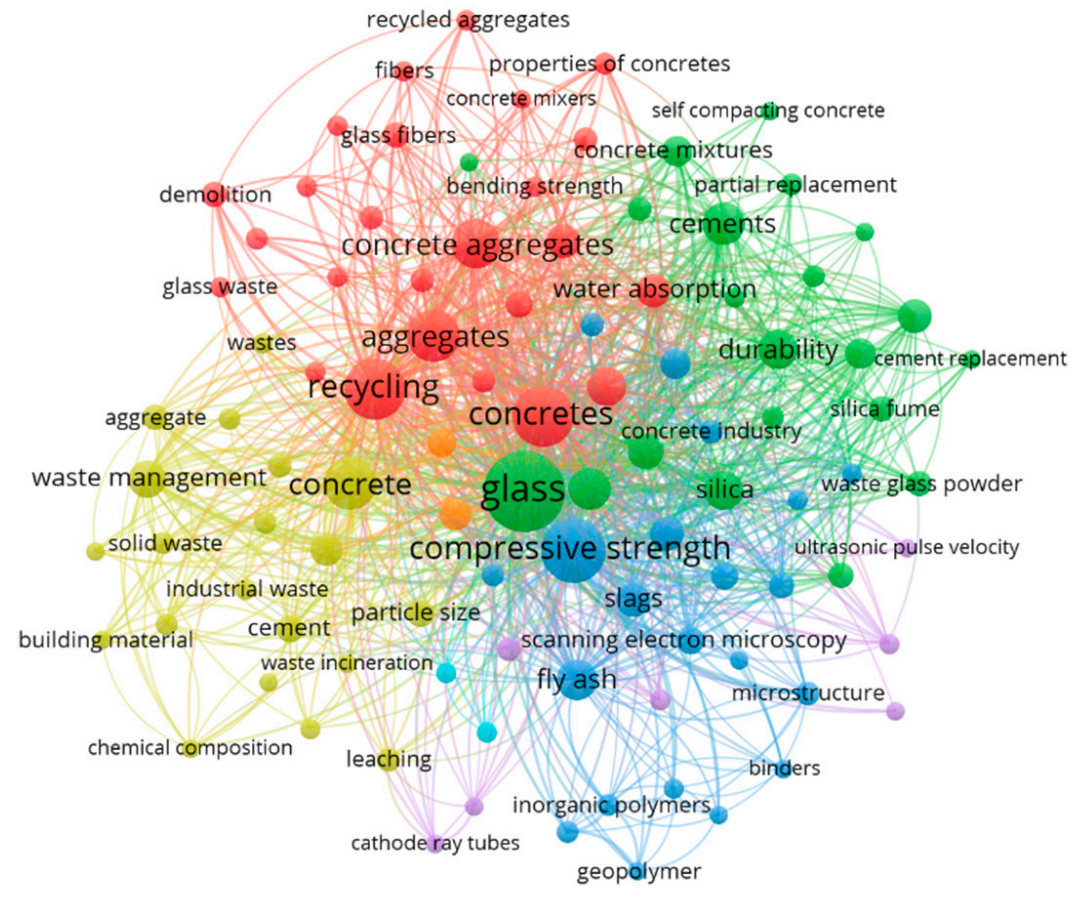

(a)

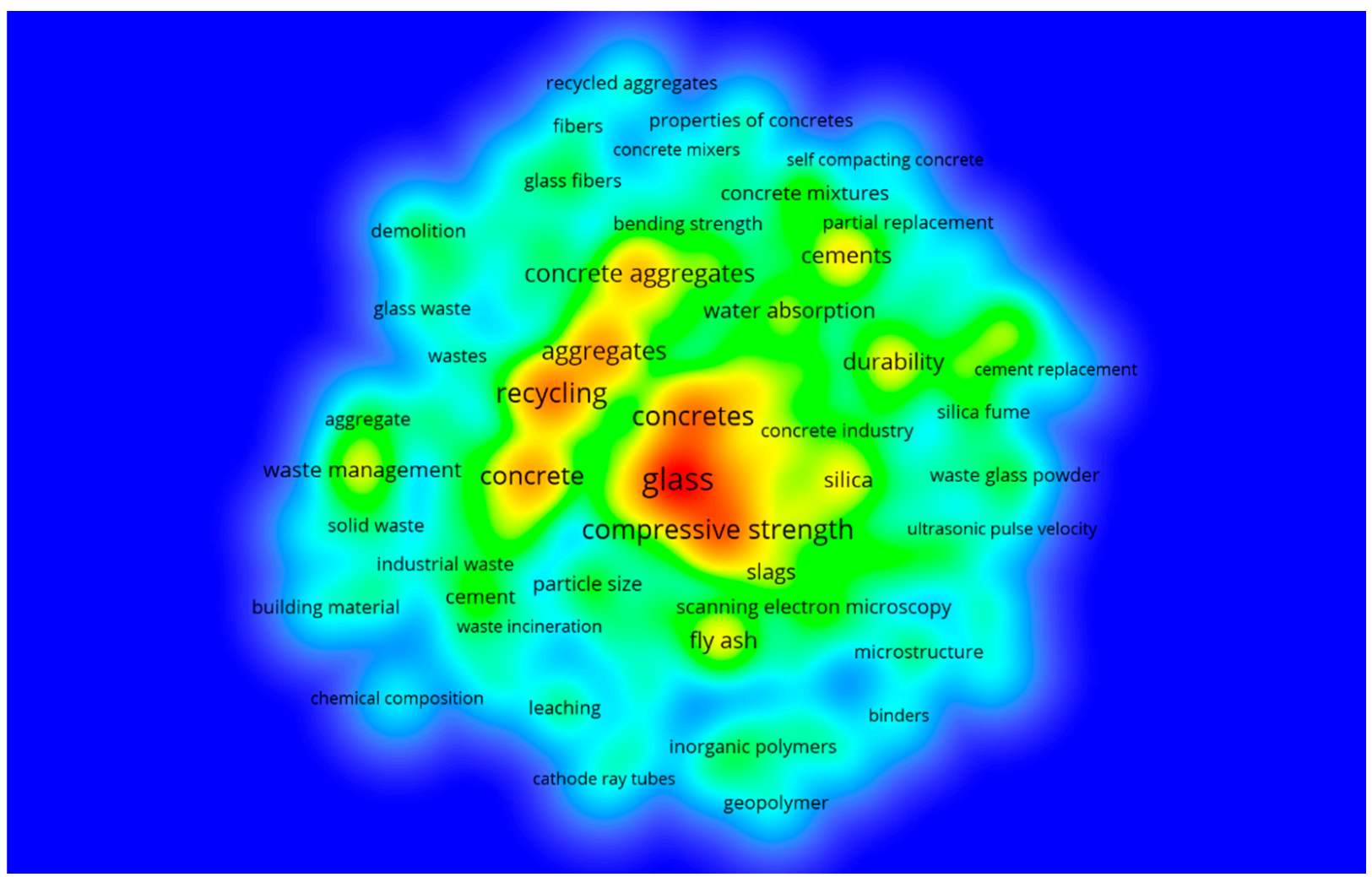

(b)

Figure 5. Mapping of keywords: (a) co-occurrence visualization; (b) density visualization. 




(a)

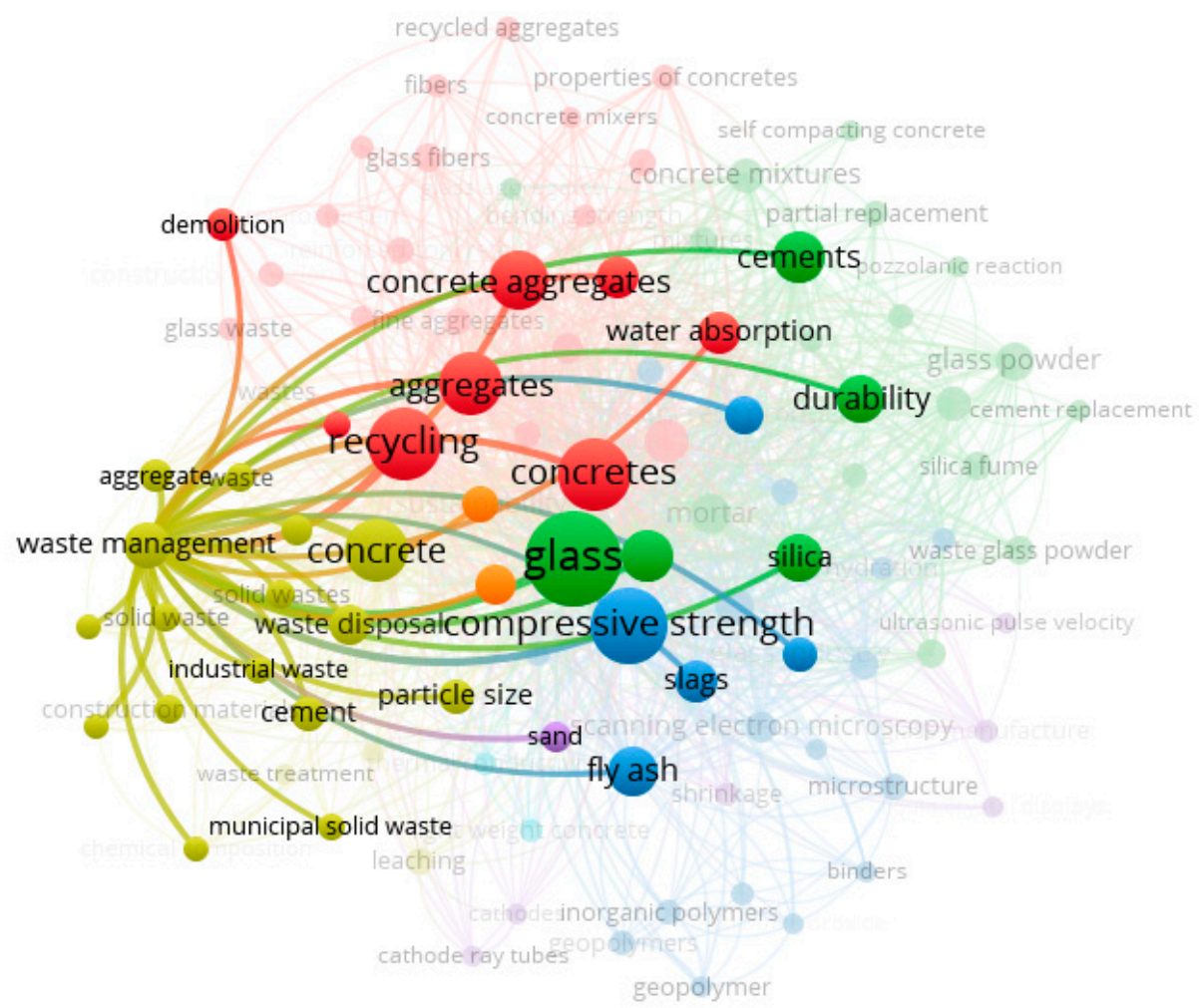

(b)

Figure 6. Cont. 


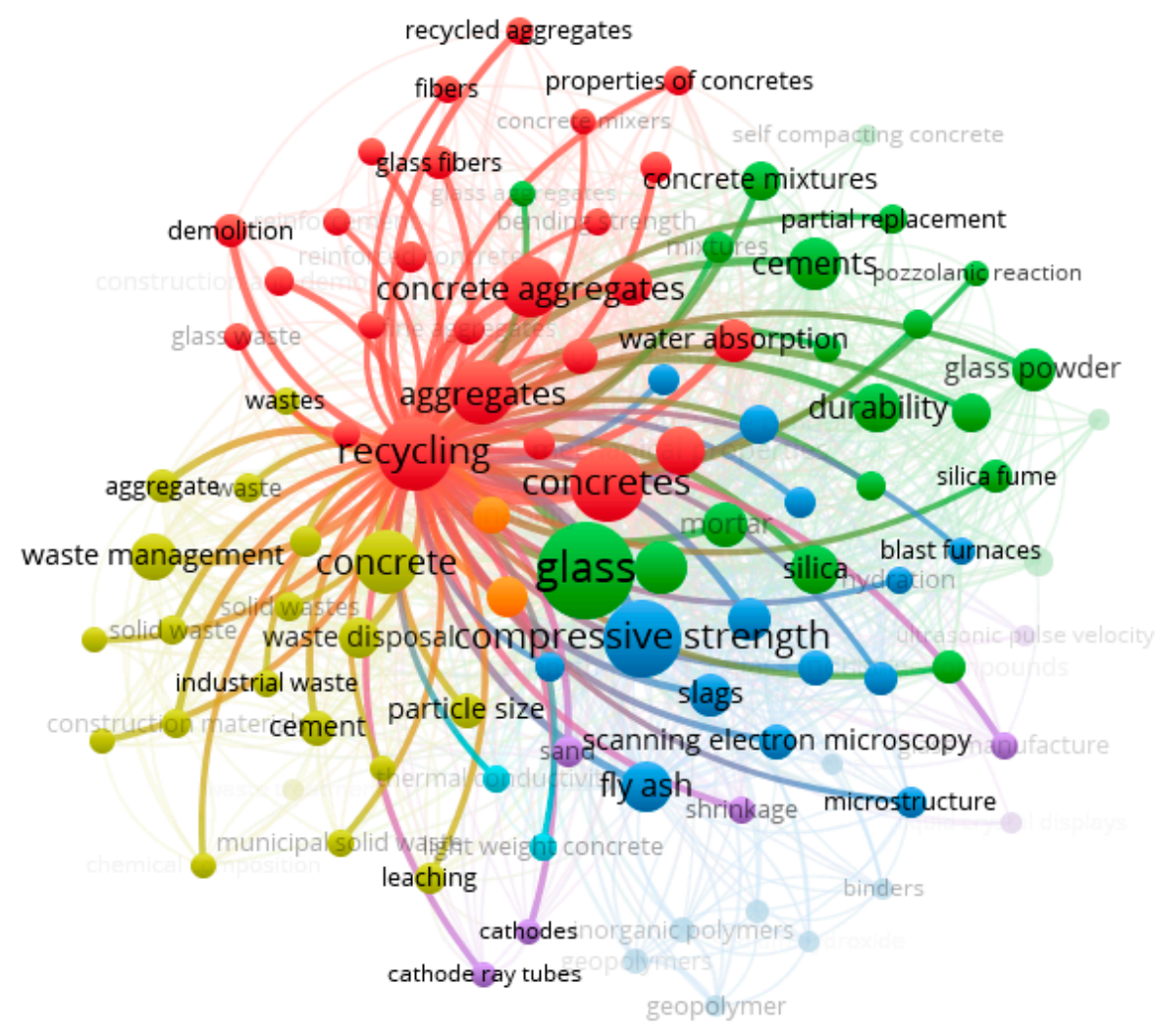

(c)

Figure 6. Connection of a keyword with others: (a) glass; (b) waste management; (c) recycling.

\subsection{Co-Authorship Mapping}

Citation counts indicate a researcher's influence in a particular field [74]. In the VOSviewer, "co-authorship" was selected as the "type of analysis", while "authors" were chosen as the "unit of analysis". The minimum number of documents required for an author was kept at 5, which resulted in 20 of the 2077 authors meeting the constraints. The top 20 authors in the field of WG in concrete for sustainable growth with the most documents and citations are listed in Table 3, according to the data retrieved from the Scopus database. The average citation count was calculated by dividing the total number of citations by the number of publications by each author. Poon C.S. was the author of the most publications (16), while Arulrajah A. was the author of the most citations (656). It will be difficult to independently assess a researcher's effectiveness. However, the author's rating will be determined by comparing all variables individually or in conjunction with one another. For instance, if the total number of documents is compared, the top three authors are Poon C.S with 16, Arulrajah A. with 13, and Tagnit-Hamou A. with 12 publications. Alternatively, if the number of citations is compared, the author's ranking would be Arulrajah A. with 656, Shi C. with 624, and Poon C.S. with 567 citations. Additionally, when comparing average citations, the authors are ranked as follows: Shi C. with 125, Poon C.-S. with 75, and Ling T.-C. with 54 average citations. Figure 7 illustrates the visualization of authors with a minimum of 5 documents and the linkage of the most prominent author. Of the 20 authors, only 4 have been linked. It was observed that authors from different regions are not connected to each other based on citations in the field of WG utilization in concrete. 
Table 3. Top researchers.

\begin{tabular}{cccccc}
\hline S/N & Author & Documents & Citations & $\begin{array}{c}\text { Average } \\
\text { Citations }\end{array}$ & $\begin{array}{c}\text { Total Link } \\
\text { Strength }\end{array}$ \\
\hline 1 & Poon C.S. & 16 & 567 & 35 & 11 \\
2 & Arulrajah A. & 13 & 656 & 50 & 16 \\
3 & Wang H.-Y. & 12 & 321 & 27 & 4 \\
4 & Tagnit-Hamou A. & 12 & 302 & 25 & 0 \\
5 & Horpibulsuk S. & 11 & 454 & 41 & 15 \\
6 & Poon C.-S. & 7 & 525 & 75 & 4 \\
7 & Ling T.-C. & 7 & 378 & 54 & 5 \\
8 & Lu J.-X. & 6 & 83 & 14 & 1 \\
9 & Shi C. & 5 & 624 & 125 & 0 \\
10 & Brouwers H.J.H. & 5 & 177 & 35 & 15 \\
11 & Dinis M.L. & 5 & 150 & 30 & 15 \\
12 & Fiúza A. & 5 & 150 & 30 & 15 \\
13 & Meixedo J.P. & 5 & 150 & 30 & 9 \\
14 & Ribeiro M.C.S. & 5 & 150 & 30 & 0 \\
15 & Mohammadinia A. & 5 & 122 & 24 & 4 \\
16 & Lin K.-L. & 5 & 108 & 22 & 4 \\
17 & Olofinnade O.M. & 5 & 78 & 16 & 6 \\
18 & Ede A.N. & 5 & 75 & 15 & 14 \\
19 & Xuan D. & 5 & 69 & 10 & 4 \\
20 & Wang C.-C. & 5 & 49 & & \\
\hline
\end{tabular}

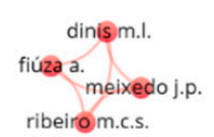

ribeirom.c.s. wângh $-y$.

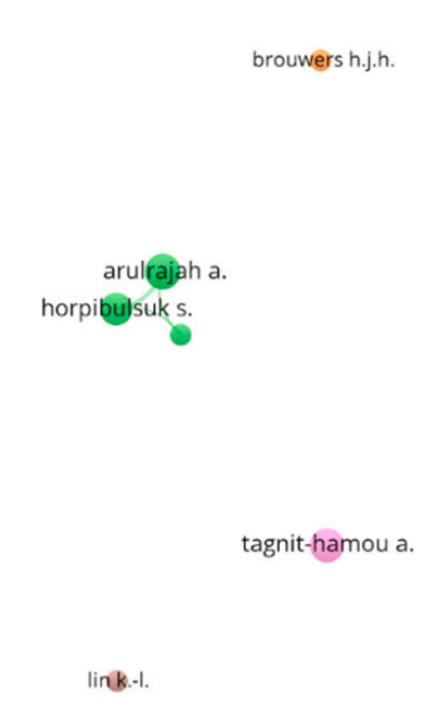

(a)

Figure 7. Cont. 


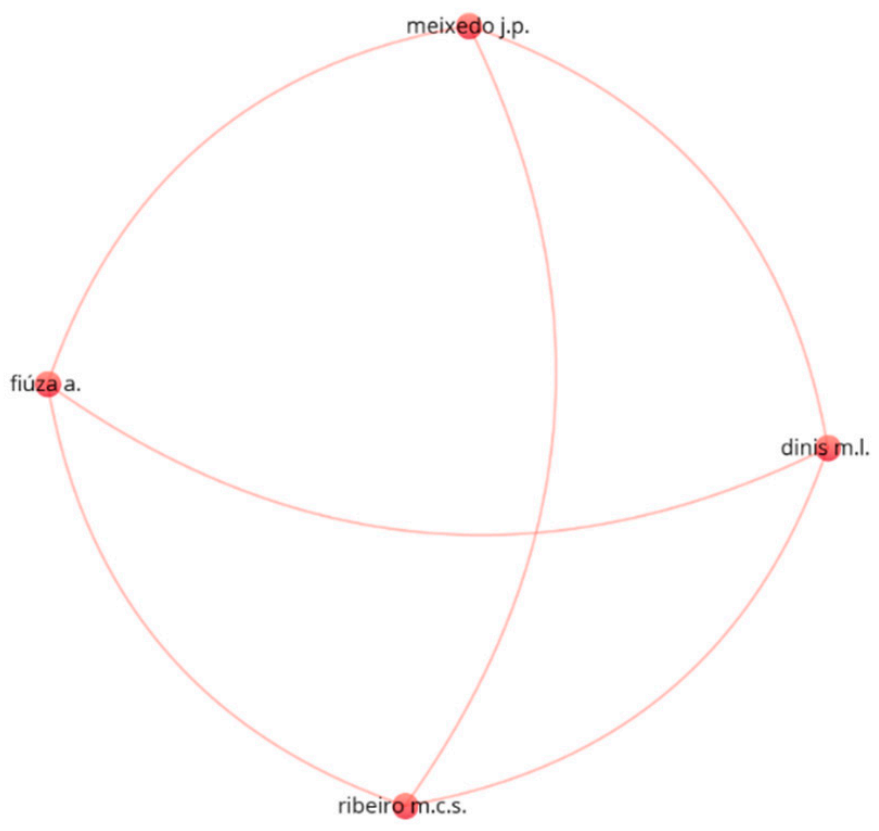

(b)

Figure 7. Visualization of co-authorship; (a) authors with minimum five documents; (b) connected authors.

\subsection{Articles Mapping}

The number of citations a research article receives indicates its impact on a particular field of study. Articles with a high citation count will be considered a landmark in the history of science. To analyze document citations, the "type of analysis" was set to "bibliographic coupling" and the "unit of analysis" to "document" in the VOSviewer. A document's minimum citation count was set to 50, and 102 of the 737 records adhered to these boundary requirements. The top 20 highly cited research articles, their authors, and the year of publication are listed in Table 4. Meyer C. [75] had the maximum citations of 691 on their article titled "The greening of the concrete industry". However, Shayan A. [76] and Topcu I.B [39] had 363 and 342 citations on their respective articles and have been ranked in the top three. Figure 8 shows the author's visualization having the most article citations on their respective publications (Figure 8a), the top connected articles (Figure 8b), and density visualization of connected articles (Figure $8 \mathrm{c}$ ) in the present study field. It was observed that the connected documents were 88 out of 102 based on citations. The network of co-citations between the writers participating in the study of WG utilization in concrete for sustainable construction is depicted in this visualization. The closeness of the articles depicts how interconnected they are with each other in terms of citations.

Table 4. Top 20 publications based on citation count.

\begin{tabular}{ccccc}
\hline S/N & Author & Title & Citations & $\begin{array}{c}\text { Total Link } \\
\text { Strength }\end{array}$ \\
\hline 1 & Meyer C. (2009) & The greening of the concrete industry & 691 & 12 \\
2 & Shayan A. (2004) & Value-added utilisation of waste glass in concrete & 363 & 27 \\
3 & Topçu I.B. (2004) & Properties of concrete containing waste glass & 342 & 68 \\
4 & Batayneh M. (2007) & Use of selected waste materials in concrete mixes & 341 & 2 \\
5 & Park S.B. (2004) & Studies on mechanical properties of concrete containing waste & 264 & 0 \\
\hline
\end{tabular}


Table 4. Cont

\begin{tabular}{|c|c|c|c|c|}
\hline $\mathrm{S} / \mathrm{N}$ & Author & Title & Citations & $\begin{array}{l}\text { Total Link } \\
\text { Strength }\end{array}$ \\
\hline 6 & Shi C. (2007) & $\begin{array}{c}\text { A review on the use of waste glasses in the production of } \\
\text { cement and concrete }\end{array}$ & 260 & 189 \\
\hline 7 & Shayan A. (2006) & $\begin{array}{l}\text { Performance of glass powder as a pozzolanic material in } \\
\text { concrete: A field trial on concrete slabs }\end{array}$ & 248 & 62 \\
\hline 8 & Tam V.W.Y. (2006) & $\begin{array}{l}\text { A review on the viable technology for construction } \\
\text { waste recycling }\end{array}$ & 239 & 5 \\
\hline 9 & Ismail Z.Z. (2009) & $\begin{array}{l}\text { Recycling of waste glass as a partial replacement for fine } \\
\text { aggregate in concrete }\end{array}$ & 211 & 108 \\
\hline 10 & Paris J.M. (2016) & $\begin{array}{c}\text { A review of waste products utilized as supplements to } \\
\text { Portland cement in concrete }\end{array}$ & 189 & 98 \\
\hline 11 & Nassar R.-U.-D. (2012) & $\begin{array}{l}\text { Strength and durability of recycled aggregate concrete } \\
\text { containing milled glass as partial replacement for cement }\end{array}$ & 181 & 100 \\
\hline 12 & Taha B. (2008) & $\begin{array}{l}\text { Properties of concrete contains mixed colour waste recycled } \\
\text { glass as sand and cement replacement }\end{array}$ & 162 & 36 \\
\hline 13 & Puertas F. (2014) & $\begin{array}{l}\text { Use of glass waste as an activator in the preparation of } \\
\text { alkali-activated slag. Mechanical strength and } \\
\text { paste characterisation }\end{array}$ & 161 & 35 \\
\hline 14 & Matos A.M. (2012) & $\begin{array}{c}\text { Durability of mortar using waste glass powder as } \\
\text { cement replacement }\end{array}$ & 159 & 149 \\
\hline 15 & Federico L.M. (2009) & $\begin{array}{l}\text { Waste glass as a supplementary cementitious material in } \\
\text { concrete: Critical review of treatment methods }\end{array}$ & 149 & 165 \\
\hline 16 & $\begin{array}{l}\text { Torres-Carrasco M. } \\
\qquad(2015)\end{array}$ & $\begin{array}{l}\text { Waste glass in the geopolymer preparation. Mechanical and } \\
\text { microstructural characterisation }\end{array}$ & 147 & 30 \\
\hline 17 & Aly M. (2012) & $\begin{array}{l}\text { Effect of colloidal nano-silica on the mechanical and physical } \\
\text { behaviour of waste-glass cement mortar }\end{array}$ & 147 & 136 \\
\hline 18 & Jani Y. (2014) & $\begin{array}{l}\text { Waste glass in the production of cement and concrete: } \\
\qquad \text { A review }\end{array}$ & 146 & 241 \\
\hline 19 & $\begin{array}{l}\text { Pereira-De-Oliveira } \\
\text { L.A. (2012) }\end{array}$ & $\begin{array}{l}\text { The potential pozzolanic activity of glass and red-clay ceramic } \\
\text { waste as cement mortars components }\end{array}$ & 146 & 68 \\
\hline 20 & Idir R. (2010) & Use of fine glass as ASR inhibitor in glass aggregate mortars & 145 & 6 \\
\hline
\end{tabular}



(a)

Figure 8. Cont. 


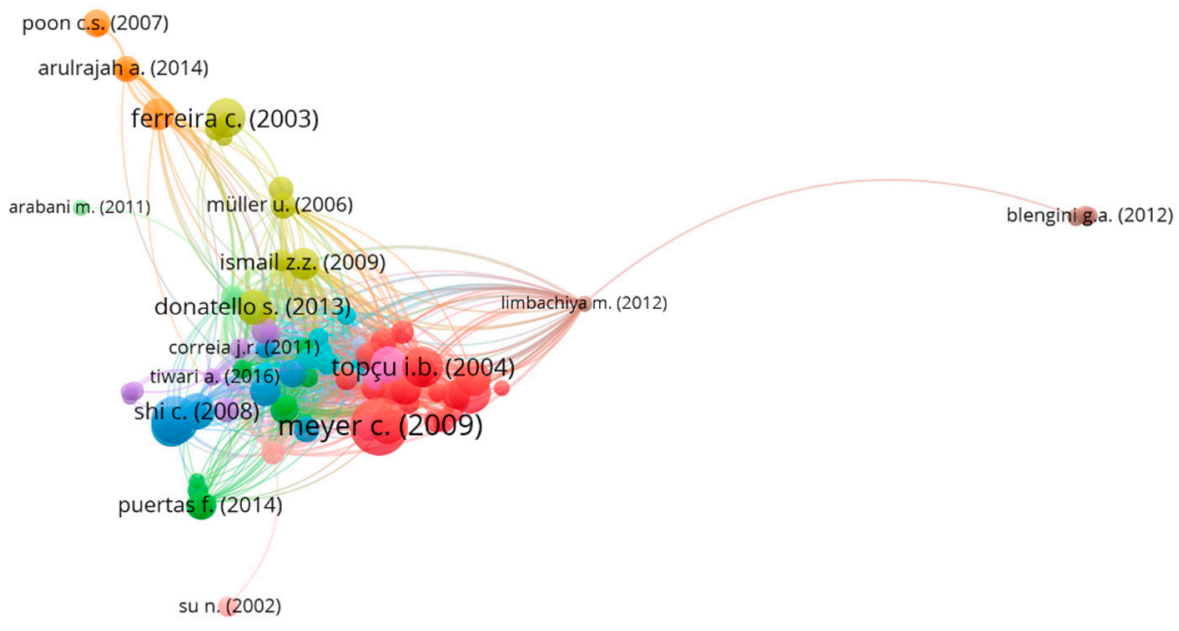

(b)

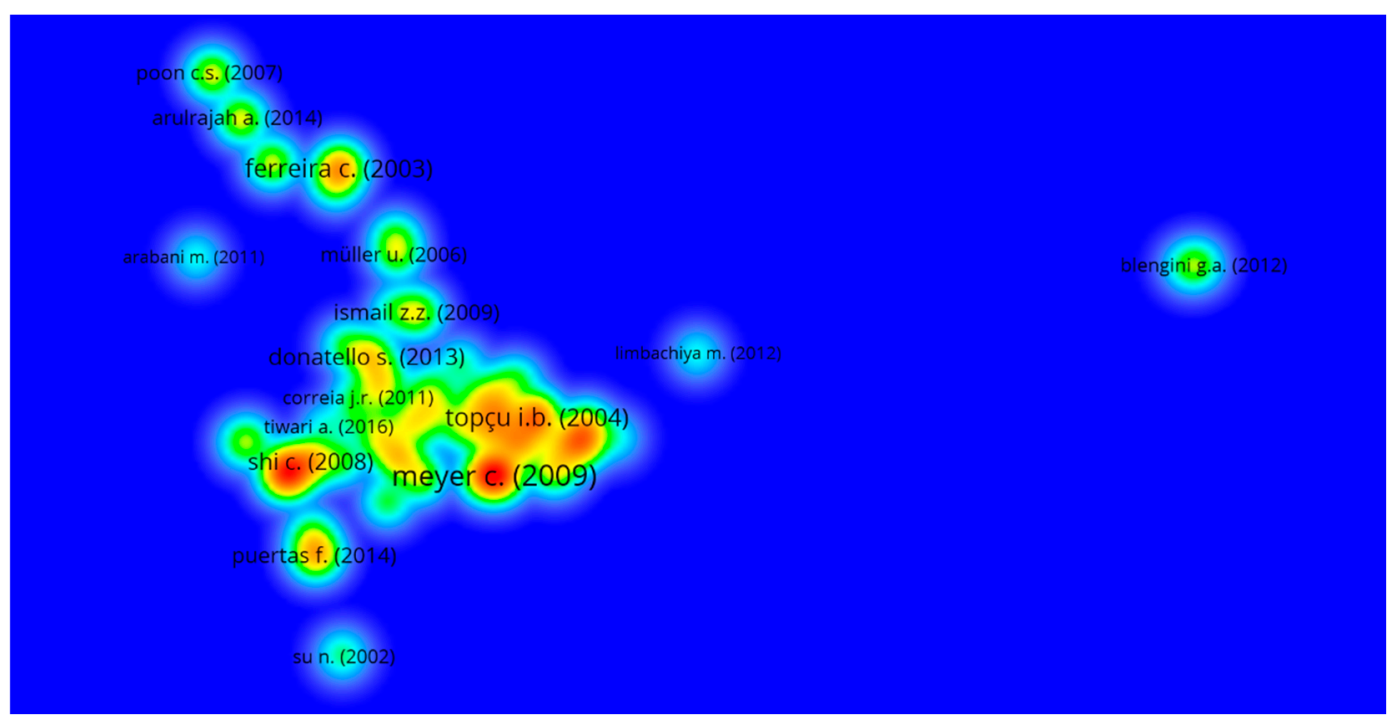

(c)

Figure 8. Mapping of documents; (a) documents with minimum 100 citations; (b) connected documents based on citations; (c) density of connected documents.

\subsection{Countries Mapping}

Certain nations have contributed more than others in the current research domain in the past and continue to do so. The visualization network was developed to help readers visualize regions that are deeply committed to sustainable construction. The "type of analysis" was "bibliographic coupling", and the "unit of analysis" was "countries". The criterion for a country's minimum number of documents was set at 5 , and 37 of 87 countries met the criterion. The top 20 active nations are listed in Table 5 based on the number of documents and citations related to the present study area. India, United States, and China contributed the most documents overall, with 126, 63, and 52 documents, respectively. While the United States, Australia, and United Kingdom were the top three participating countries in terms of citation count, with 2778,2098 , and 1857 citations, respectively. The number of documents, citations, and total link strength indicates a nation's influence on the evolution of the current research domain. The total link strength indicates the extent to which a country's documents have influenced the other countries participating in these studies. The United States had the strongest total link strength in comparison to other countries, followed by Australia and China. As a result, the aforementioned countries 
were determined to have the greatest influence on the utilization of WG in concrete for sustainable construction. Figure 9a,b illustrates the countries' connectivity and density visualization of countries that are connected through citations. The frame's size indicates the country's contribution to the field of study. Additionally, the density visualization demonstrates that the countries with the highest participation had a higher density. Future researchers will be aided in establishing scientific collaborations, producing joint venture reports, and sharing innovative techniques and ideas by the graphical representation of participating countries.

Table 5. Top 20 contributing countries.

\begin{tabular}{ccccc}
\hline S/N & Country & Documents & Citations & Total Link Strength \\
\hline 1 & India & 126 & 1581 & 15,912 \\
2 & United States & 63 & 2778 & 19,741 \\
3 & China & 52 & 1622 & 16,421 \\
4 & Australia & 49 & 2098 & 17,897 \\
5 & South Korea & 34 & 691 & 9220 \\
6 & United Kingdom & 34 & 1857 & 9041 \\
7 & Iran & 33 & 730 & 13,483 \\
8 & Taiwan & 32 & 825 & 9171 \\
9 & Canada & 28 & 1095 & 11,043 \\
10 & Hong Kong & 26 & 1425 & 10,994 \\
11 & Portugal & 22 & 1167 & 6173 \\
12 & Spain & 22 & 893 & 4421 \\
13 & Turkey & 22 & 721 & 4795 \\
14 & Iraq & 21 & 454 & 4291 \\
15 & Malaysia & 21 & 424 & 8844 \\
16 & Egypt & 20 & 816 & 7705 \\
17 & Italy & 20 & 498 & 5085 \\
18 & Thailand & 20 & 809 & 6157 \\
19 & Poland & 17 & 99 & 5883 \\
20 & Nigeria & 16 & 162 & 10,632 \\
\hline
\end{tabular}

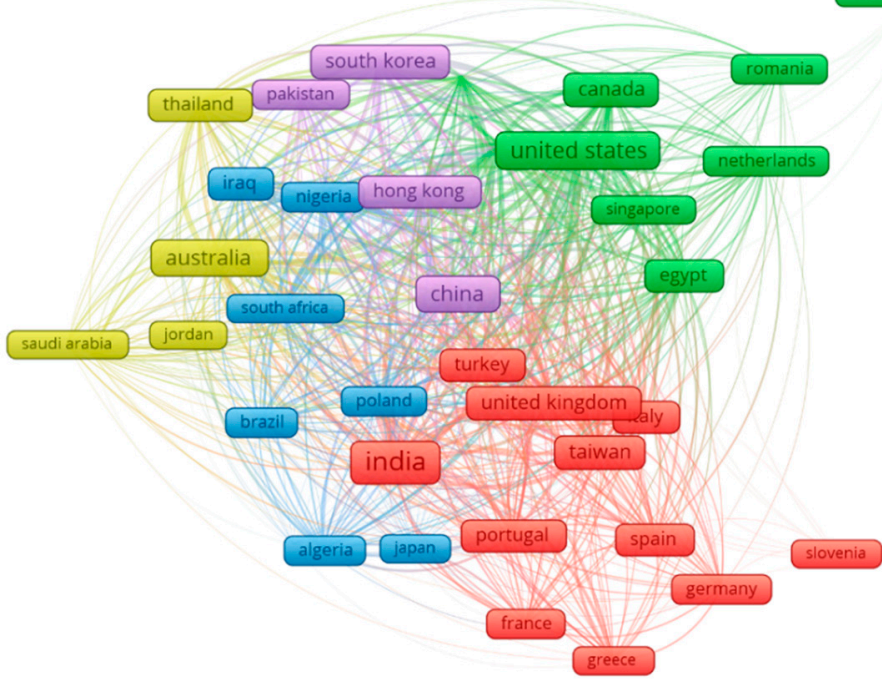

(a)

Figure 9. Cont. 


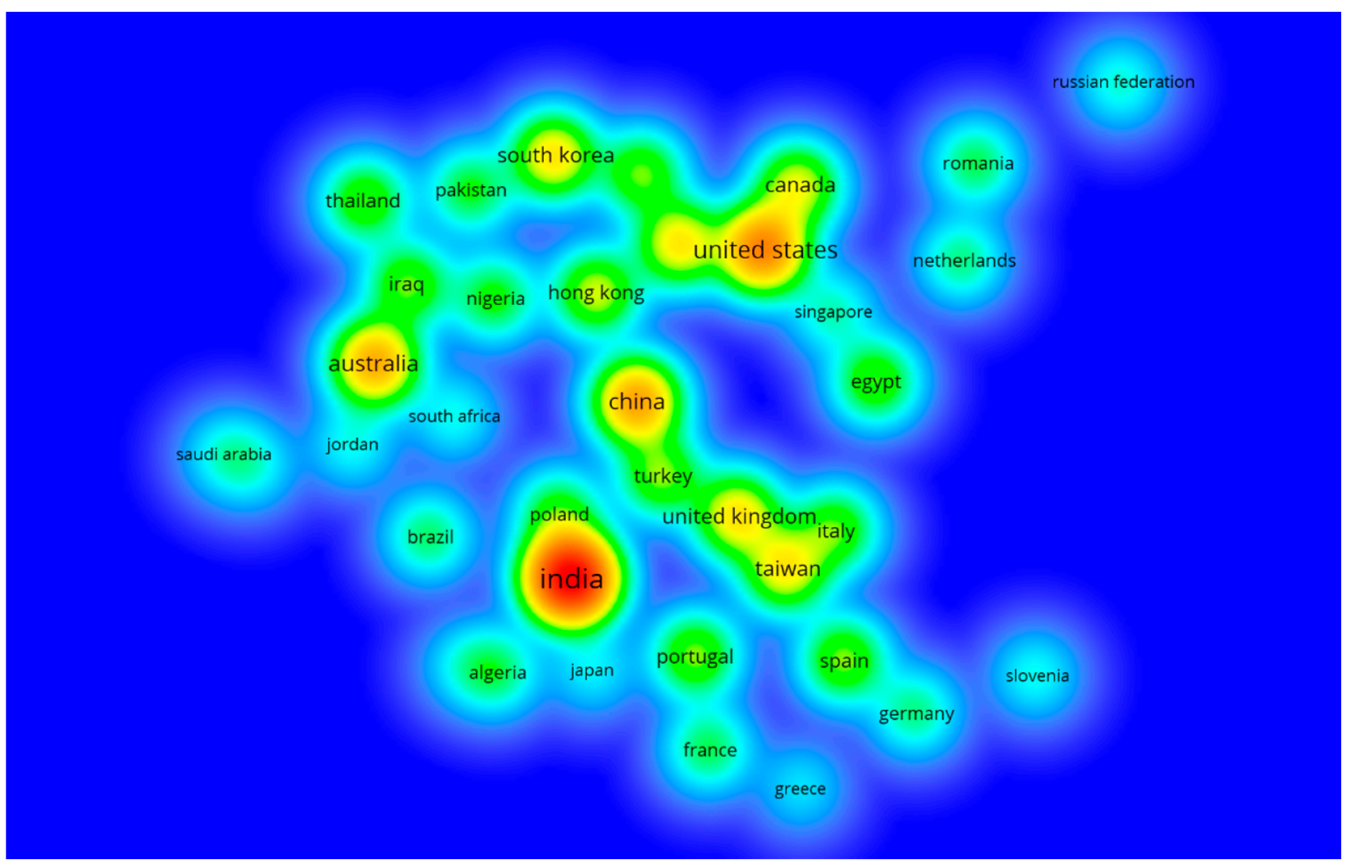

(b)

Figure 9. Countries mapping: (a) network visualization: (b) density visualization.

\section{Types and Properties of Waste Glass}

WG is classified chemically as lead, soda-lime, electric, and borosilicate glass. The most widely utilized type of glass is soda-lime glass. The main chemical composition of glass includes $\mathrm{SiO}_{2}, \mathrm{Na}_{2} \mathrm{CO}_{3}$, and $\mathrm{CaCO}_{3}$ [77]. Table 6 lists the percentage of various chemical compounds in different kinds of glass. Glass is classified according to its color into three categories: clear/flint, green, and brown/amber glass [78]. Glasses come in a variety of colors due to their chemical compositions, which relate to distinct levels of color impurity. Color impurity is limited to $4-6 \%, 5-30 \%$, and $5-15 \%$ in clear, green, amber glass, respectively [77]. Glass is classified according to its application into six categories, namely, plate glass, container glass, continuous filament glass, mineral wool insulation, specialty glass, and domestic glass or tableware [77]. Between these types, plate and container glass are typically made of soda-lime glass; domestic glass is typically made of lead or soda-lime glass; continuous filament glass is typically made of electric glass; borosilicate glass is used to insulate mineral wool, and specialty glass is frequently made of borosilicate or soda-lime glass.

Table 6. Chemical composition of various kinds of waste glass [77].

\begin{tabular}{ccccccc}
\hline \multirow{2}{*}{ Glass Type } & \multicolumn{7}{c}{ Chemical Compound (\%) } \\
\cline { 2 - 7 } & $\mathbf{S i O}_{\mathbf{2}}$ & $\mathbf{N a}_{\mathbf{2}} \mathbf{O}+\mathbf{K}_{\mathbf{2}} \mathbf{O}$ & $\mathbf{C a O}$ & $\mathbf{A l}_{\mathbf{2}} \mathbf{O}_{3}$ & $\mathbf{B}_{\mathbf{2}} \mathbf{O}_{\mathbf{3}}$ & $\mathbf{P b O}$ \\
\hline Soda-lime & $71-75$ & $12-16$ & $10-15$ & - & - & - \\
Lead & $54-65$ & $13-15$ & - & - & - & $25-30$ \\
Borosilicate glass & $70-80$ & $4-8$ & - & 7 & $7-15$ & - \\
Electric & $52-56$ & $0-2$ & $16-25$ & $12-16$ & $0-10$ & - \\
\hline
\end{tabular}

\section{Waste Glass Utilization in Cement-Based Materials}

WG can be utilized in CBMs as aggregate replacement and cement replacement. Thus, it conserves natural resources, solves waste management problems, reduces $\mathrm{CO}_{2}$ emission by decreasing cement demand, protects the environment from toxic chemicals, and produces cost-effective composites. Therefore, the utilization of WG in construction materials is a better approach for sustainability in construction. In this section, the effect of utilizing WG 
on fresh and hardened properties of CBMs, including workability, compressive strength (CS), split-tensile strength (STS), and flexural strength (FS), are reviewed. Furthermore, the microstructure and durability of composites containing WG are investigated. Different limitations associated with WG use in CBMs and their possible solution are reported.

\subsection{Mechanical Properties of Cement-Based Materials Containing Waste Glass as Natural Aggregate Replacement \\ 6.1.1. Workability}

WG's effect on the workability of fresh concrete has been reported to be inconsistent in previous studies. Partial substitution of sand with WG improved workability. For instance, Elaqra et al. [79] used a soda-lime glass (size: $<20 \mu \mathrm{m}$ ) and found that increasing the replacement percentage from $0 \%$ to $30 \%$ increased the slump from $130 \mathrm{~mm}$ to $190 \mathrm{~mm}$. However, the utilization of WG decreased the workability of concrete. For example, an electric glass (size: $<150 \mu \mathrm{m}$ ) reduced the slump from $200 \mathrm{~mm}$ to $45 \mathrm{~mm}$ as the amount of WG increased from $0 \%$ to $40 \%$ [80]. The above-mentioned inconsistencies in WG's effect on the workability of composites are the result of two competing effects. Firstly, glass improves workability by reducing water adsorption and friction due to its dense microstructure and smooth surface. Indeed, WG has been used to create SCC that is vibration-free during construction [81-85]. Secondly, glass can reduce workability due to extremely fine glass particles; the surface-to-volume ratio increases, increasing water adsorption. Thus, the size of the glass particles is a critical parameter in determining their effect on workability. However, if coarser glass particles are utilized, the irregular shape of the glass particles improves mechanical interlocking among adjacent particles and ultimately reducing the workability [86]. This is consistent with Topcu and Canbaz's [39] findings, i.e., the addition of coarse glass particles (size: $16 \mathrm{~mm}$ ) decreased the workability of the fresh mix. With increasing glass particle size, the surface-to-volume ratio decreases, resulting in a small quantity of paste or mortar adsorbed on the surface of glass particles for lubricating nearby glass particles. This effect of under-lubrication may have been facilitated by the glass particle's smooth and dense surface.

\subsubsection{Compressive Strength}

According to the literature, there is a detrimental effect on CS of composites containing WG as a partial or complete substitute of NA, as shown in Figure 10. Mostly, a decreasing trend is observed with the increasing replacement ratio of WG. However, using a smaller size WG at a lower replacement ratio can enhance the CS by filling the voids in the matrix. Liu et al. [87] found a decrease in CS by $2.9 \%, 10 \%$, and $15.7 \%$ when coarser WG (5-10 mm) was used at $10 \%, 20 \%$, and $30 \%$ content, respectively. Though, using finer WG (size: $<4.75 \mathrm{~mm}$ ), the reduction in CS was minimal. They reported two primary explanations for this decline. Firstly, the WG aggregate has a lower strength than the NA aggregate, and secondly, the smooth surface of the WG aggregate affects its binding with cement paste, reducing the strength of the concrete. A similar pattern of reduction in CS with the increasing amount of WG in composites as an aggregate replacement was also noted by other researchers [88-90]. Conversely, Ismail and Hashmi [91] and Abdallah and Fan [92] found a $4.3 \%$ and $4.9 \%$ increase in CS, respectively, when fine aggregate was replaced at $20 \%$ by WG. Similarly, Malik et al. [93] investigated the CS of composites containing finer WG particles (size: $<1.18 \mathrm{~mm}$ ) at various replacement ratios. The results revealed that composites containing 10\%, 20\%, and 30\% WG enhanced the CS by $20.0 \%, 25.1 \%$, and $9.8 \%$, respectively, compared to the reference mix. However, at $40 \%$ replacement ratio, the CS decreased by $8.5 \%$ than the reference mix, as shown in the figure. Thus, the use of finer WG at a lower replacement ratio could enhance the CS by filling voids in the matrix, while coarser WG reduces the CS because of weak ITZ between WG aggregate and cement matrix. 




Figure 10. Effect of waste glass as a natural aggregate replacement on 28-days compressive strength.

\subsubsection{Split-Tensile Strength}

The WG usage as an NA replacement also has an unfavorable effect on the STS of composites, as depicted in Figure 11. The STS decreases with the increasing replacement ratio of WG, as reported by most researchers [87,90,93,94]. Liu et al. [87] reported a decrease in STS than that of reference mix by $8.5 \%, 14.1 \%, 21.1 \%$, and $25.4 \%$ when WG replaced natural fine aggregate at $25 \%, 50 \%, 75 \%$, and $100 \%$ ratios, respectively. Song et al. [90] found a decrease in STS compared to control mix by $2.3 \%, 2.3 \%, 5.2 \%, 6.8 \%$, and $10 \%$ when NA was replaced by $20 \%, 40 \%, 60 \%, 80 \%$, and $100 \%$ WG, respectively. However, Abdallah and Fan [92] and Malek et al. [95] found an increase in STS of WG composites than NA composites using lower content (up to $20 \%$ ) of WG. It can be concluded that WG with smaller particle size and used in lower proportions positively influences the STS of composites.

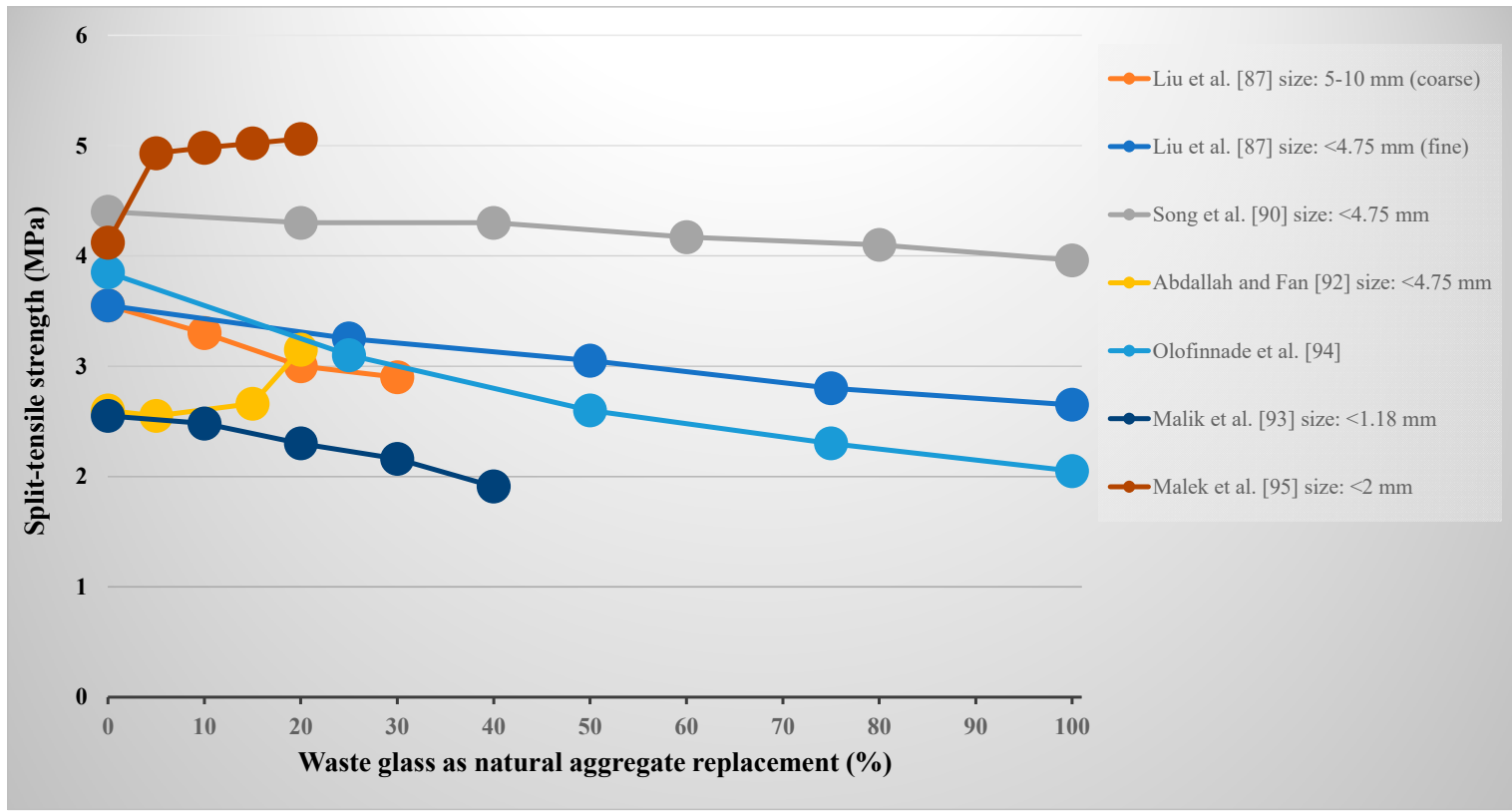

Figure 11. Effect of waste glass as a natural aggregate replacement on 28-days split-tensile strength. 


\subsubsection{Flexural Strength}

Figure 12 depicts the influence on FS of composites with increasing WG content as the NA replacement. It shows that at lower WG content, the FS of composites can be improved, while higher WG content results in decreasing FS. However, the reduction in FS is minimal compared to CS and STS. Wang and Huang [88] found improvement in FS of $14.7 \%$ at a $10 \%$ replacement ratio, while a further increase in WG decreased FS compared to the reference sample without WG. The study of Ismail and Hashmi [91] and Abdallah and Fan [92] reported improvement in FS of WG aggregate composites in comparison with the NA composites. The improvement in FS with WG addition may be attributed to the pozzolanic properties of glass, which helped to improve the microstructure of the matrix [91]. Kim et al. [96] and Sikora et al. [97] observed a drop in FS of WG composites in comparison to the NA composites. The reduction in FS was more at higher WG content as aggregate replacement. This could be because the smooth surface of WG relative to the NA having lower adhesion to the surrounding matrix than that of NA. However, Malek et al. [95] reported increasing FS with increasing WG percentage up to $20 \%$ with an increment of $5 \%$. At a $20 \%$ replacement ratio, the FS increased by $14.3 \%$. The reason is the use of fine WG (size: $<2 \mathrm{~mm}$ ), which helped improve the microstructure by filling pores in the matrix. Thus, the use of WG can improve the properties of composites if used in smaller sizes and lower replacement ratios. This is because the finer WG can improve the microstructure by filling voids in the matrix [93]. In addition, a higher replacement ratio and a larger size of WG used as NA replacement reduced the properties of composites. This may be attributed to the more glass-matrix interfaces, and the smooth surface of WG may reduce the interfacial bond strength, resulting in decreased strength of composites [90].

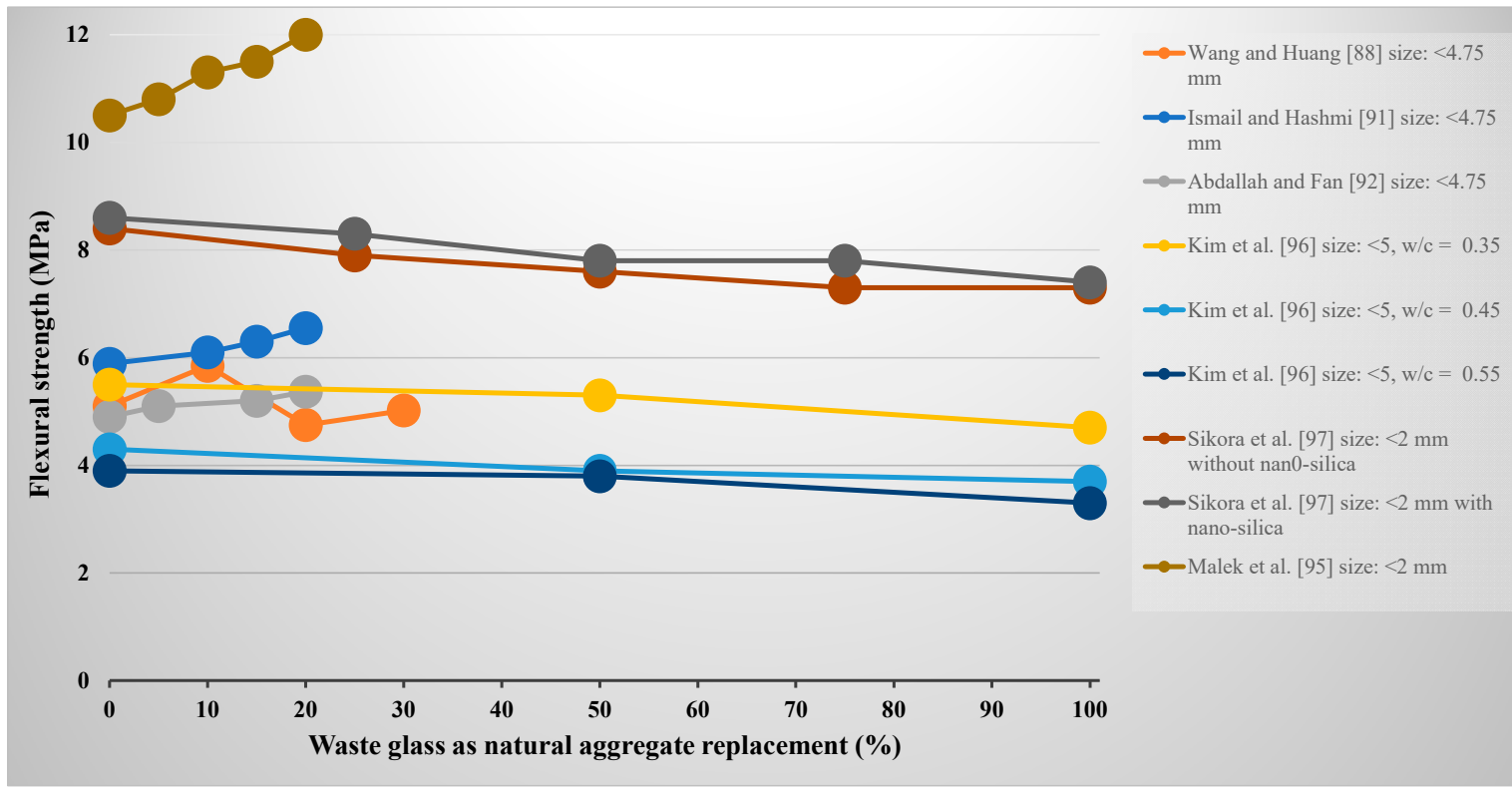

Figure 12. Effect of waste glass as a natural aggregate replacement on 28-days flexural strength.

6.2. Mechanical Properties of Cement-Based Materials Containing Waste Glass as Cement Replacement

6.2.1. Workability

The finer/powder WG is usually used as cement replacement. Islam et al. [98] performed a flow test on mixes of WG powder mortar. Water/binder ratio $(\mathrm{w} / \mathrm{b})$ was kept 0.5 for mix preparation. The findings indicated that as the percentage of WG as cement substitute increased, the flow diameter increased. The flow diameter of the reference mix was $132.5 \mathrm{~mm}$, while the flow diameter of mortar samples containing $25 \%$ WG as cement replacement was $135 \mathrm{~mm}$. As a result, a slight increase in flow was observed. 
Aliabdo et al. [51] evaluated the workability of WG powder-modified concrete using a slump test. It was observed that the slump of mix containing WG powder as a substitute for cement improved as the WG powder content increased. The smooth surface and minimal water absorption capacity of WG powder may contribute to the slump increase. Additionally, WG powder contains coarser particles than cement, which might have caused the improvement in a slump. Soliman and Tagnit-Hamou [99] also demonstrated that incorporating WG powder in place of cement increased the workability of concrete, which may be due to the low water absorption and smooth texture of WG powder than the cement particles. Another factor contributing to increase the workability is the dilution of cement. The reasons outlined above account for the reduction in the formation of hydration products of cement during the initial time. As a result, there is an insufficient number of products available for combining disparate particles. As WG powder has a smaller specific surface area than cement, the total surface area of the cement and WG powder mixture is reduced. Therefore, it decreased the water requirement for particle surface lubrication and resulted in an increased slump.

\subsubsection{Compressive Strength}

Islam et al. [98] performed a CS test on mortar specimens containing recycled WG as cement replacement. Compared to controlled mortar specimens, recycled WG mortar had a lower CS at the age of 7, 14, 28, and 56 days. At 90 days, an increase in CS was observed; the highest CS was obtained with a 10\% cement replacement. Similarly, $15 \%$ cement replacement at 180 days and $20 \%$ cement replacement at 365 days exhibited maximum CS. The reason could be the pozzolanic behavior of glass, which reacted slowly and improved the microstructure of the matrix at later ages and resulted in improved CS. Figure 13 is generated based on the past studies depicting the variation in 28-days CS with increasing WG content as cement replacement. A slight increase in CS can be observed at lower replacement ratios. Rehman et al. [82] used WG powder as cement replacement $(20 \%$, $30 \%$, and $40 \%$ ) and steel slag as a fine aggregate replacement $(40 \%, 60 \%$, and $80 \%)$ in SCC and investigated their influence on MPs. They observed an increase in CS when $20 \%$ cement is replaced by WG powder, but it decreased as the WG powder content is increased further. When the proportions of all other ingredients were constant, increasing the steel slag content increased the CS of SCC. At constant WG powder content, the CS of concrete improved as the steel slag content increased. The maximum increase in CS was observed by $11 \%$ in comparison with the control specimen when $20 \%$ WG powder was used in place of cement, and $80 \%$ steel slag was used in place of fine aggregate. On the other hand, there was a slight decrease in CS of SCC as the WG powder content increased while the steel slag content was kept constant. The minimum CS was 5.7\% lower than the control specimen when WG powder and steel slag were used in place of $40 \%$ cement and $40 \%$ fine aggregate, respectively. The increase in CS with the addition of steel slag could be attributed to the pozzolanic action of steel slag or the difference in hardness between steel slag and the replaced aggregates. Al-Zubaid et al. [100] studied the effect of brown, green, and neon glass on MPs of concrete used as cement replacement by $11 \%$, $13 \%$, and $15 \%$. The best results of CS were observed with neon glass at $13 \%$ content due to the high concentration of $\mathrm{SiO}_{2}(68 \%)$ in neon glass, combined with the high $\mathrm{CaO}$ content $(66.11 \%)$ in cement, and their combination with water formed a significant amount of $\mathrm{CaCO}_{3}$ during the hydration process. Anwar [101] also observed improvement in CS at lower content of WG powder. At 10\% WG powder content, the CS improved by $16.6 \%$ than the reference sample. The increase in CS occurred due to the pozzolanic reaction of glass powder. Because the glass powder acts as a pozzolanic material, it reduces the effect of carbonation and increases the strength of concrete. Thus, the smaller particle size of the glass powder interacts more readily with the lime in the cement, resulting in increased CS in the concrete. Aliabdo et al. [51] reported a 5.1\% increase in CS for $33 \mathrm{MPa}$ concrete containing $5 \% \mathrm{WG}$ powder in place of cement when compared to the reference mix. Whereas CS decreased with further addition of WG powder, as shown in the figure. 
Additionally, the CS of concrete mix grade $45 \mathrm{MPa}$ increased by $2.5 \%$ at $5 \%$ replacement and $4.8 \%$ at $10 \%$ replacement compared to the reference mix. When more than $10 \%$ of the cement was replaced by WG powder, a decrease in CS was observed; this decrease could be attributed to the increased percentage of cement replacement, which resulted in cement dilution. A similar trend was also observed from various studies with the use of WG as cement replacement [102]. Hence, WG powder as cement replacement is preferable only at lower replacement ratios.

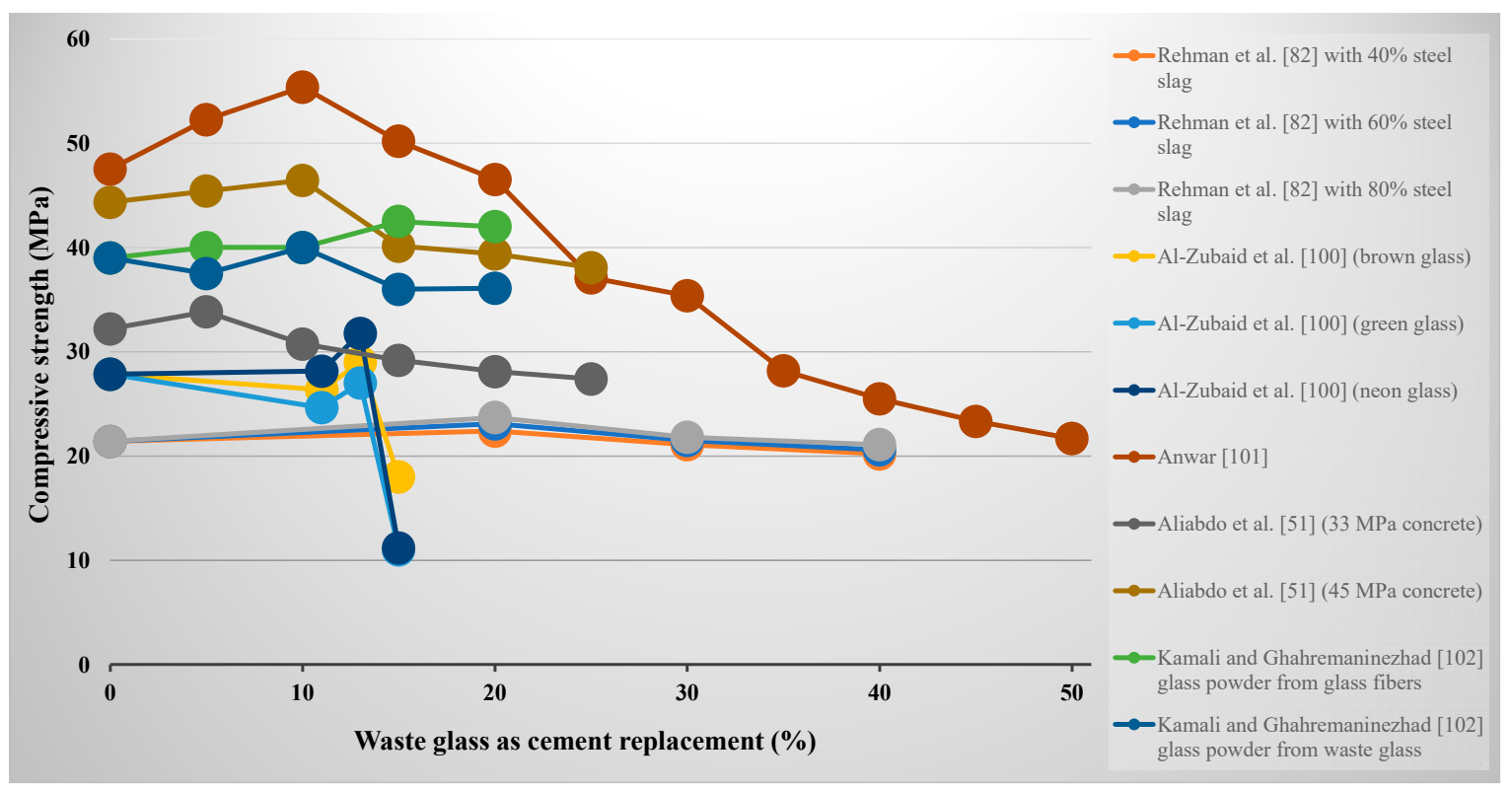

Figure 13. Effect of waste glass as cement replacement on 28-days compressive strength.

\subsubsection{Split-Tensile Strength}

The effect of using WG as cement replacement on STS has been shown in Figure 14. It also indicates that at lower content of WG, the STS can be increased while higher content of WG decreases the STS compared to the reference samples without WG. Similar to the CS, Rehman et al. [82] noted that the maximum improvement in STS was $13.2 \%$ when $20 \%$ of cement was replaced with WG powder, and $80 \%$ of cement was replaced with steel slag. The minimum STS was 5.6\% less than that of the control mix when $40 \%$ steel slag and $40 \%$ glass powder were used as cement and aggregate replacements, respectively. Whereas, Al-Zubaid et al. [100] mostly found a decrease in STS with the addition of different types of WG in concrete. However, using green glass at $13 \%$ replacement of cement showed improvement in STS by $16.2 \%$ than the control mix. Aliabdo et al. [51] described enhancement in STS by $16.6 \%, 19.4 \%$, and $5.9 \%$ for $33 \mathrm{MPa}$ concrete containing $5 \%, 10 \%$, and $15 \%$ WG powder, respectively, when compared to the control mix. Whereas STS decreased by $10 \%$ and $13.8 \%$ when $20 \%$ and $25 \%$ WG powder were substituted for cement in a $33 \mathrm{MPa}$ concrete mix, respectively. Additionally, for $5 \%, 10 \%$, and $15 \%$ replacement in $45 \mathrm{MPa}$ grade concrete, the STS increased by $11.7 \%, 13.0 \%$, and $18.1 \%$, respectively. Whereas, at $20 \%$ and $25 \%$ replacement, a slight decrease in STS of $1.0 \%$ and $2.3 \%$, respectively, was observed. STS decreases when more than $20 \%$ of cement is replaced with WG powder. The reasons for the improvement in STS at lower WG contents and reduction in STS at higher WG contents are the same as described earlier for CS.

\subsubsection{Flexural Strength}

The influence of WG powder as cement replacement on the FS of composites has been displayed in Figure 15. It also shows an almost similar trend as CS and STS. For instance, the results of Rehman et al. [82] showed enhanced FS at 20\% and 30\% contents of WG powder 
while at $40 \%$ content of WG powder, the FS reduced compared to the reference sample. The highest value of FS was observed at $20 \%$ content of WG powder as cement replacement and $80 \%$ steel slag as fine aggregate replacement. Similar to the CS, the maximum FS was observed with neon glass at a $13 \%$ replacement ratio [100]. Also, the addition of WG with up to $20 \%$ content exhibited improvement in FS while a further increment in WG content reduced the FS than the reference sample [101]. Hama [103] also reported maximum FS at $20 \%$ replacement of cement by WG powder. However, several studies reported a reduction in FS with the utilization of WG powder as cement replacement $[100,104]$, as shown in the figure. The reasons for the CS behavior of composites with WG addition also apply to the flexural behavior.



Figure 14. Effect of waste glass as cement replacement on 28-days split-tensile strength.

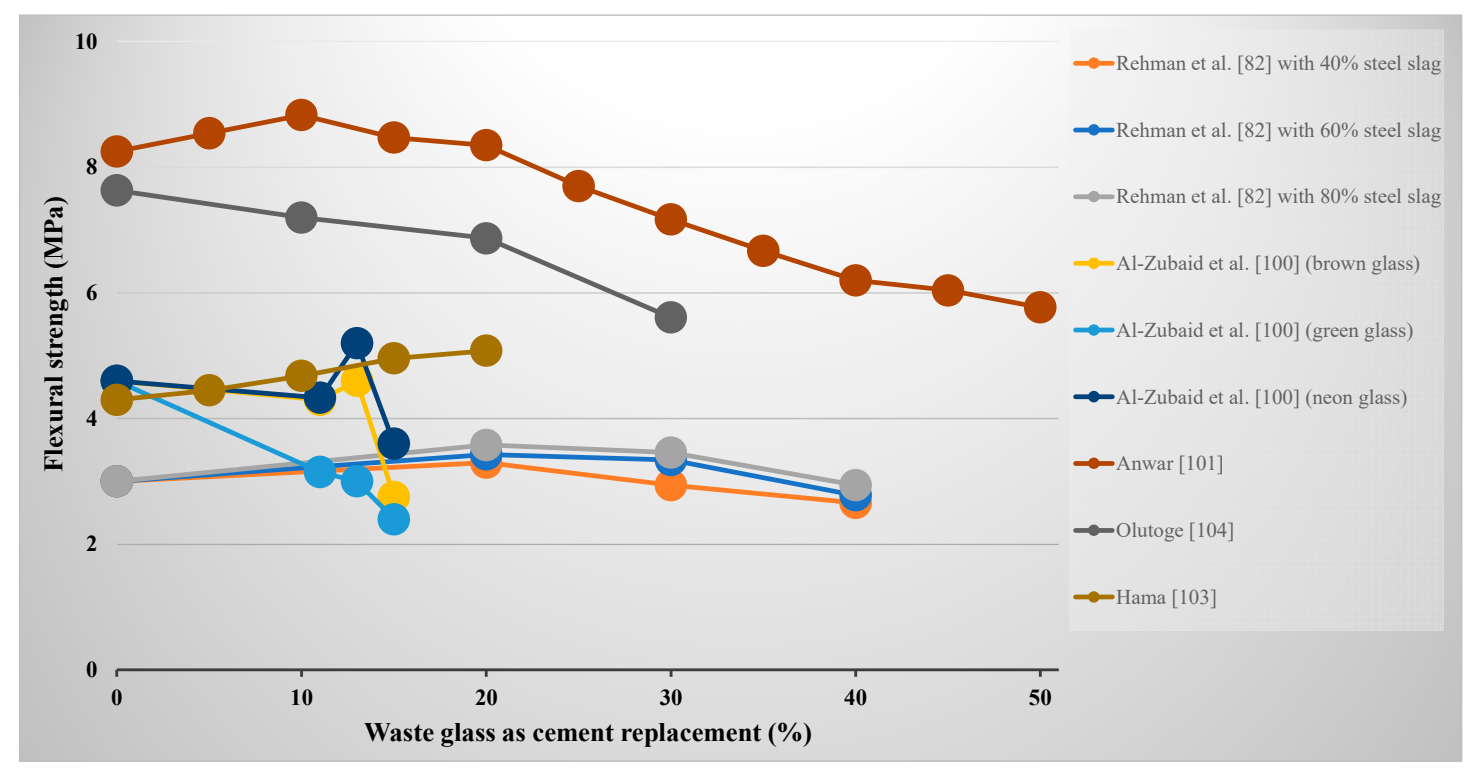

Figure 15. Effect of waste glass as cement replacement on 28-days flexural strength.

\subsection{Microstructure of Cement-Based Materials Containing Waste Glass}

The microstructure study of various past studies revealed that the size of WG used as aggregate replacement greatly influences the ITZ and porosity of the matrix. Afshinnia and 
Rangaraju [105] found weak glass-matrix ITZ and high porosity when coarser WG was used as an aggregate replacement, compared to the NA concrete, as depicted in Figure 16. As illustrated in the figure, WG aggregates have a smooth particle surface that interfaces with the cement paste, resulting in minimal mechanical interlocking between the two phases. The weak bond between WG and cement matrix is also reflected in the mechanical characteristics of composites. Conversely, the use of finer WG as an aggregate replacement can improve the microstructure of composites [105]. Soliman and Hamou [106] performed SEM analysis to study the microstructure of composite containing $50 \%$ quartz sand and $50 \%$ recycled WG with a mean particle size of $275 \mu \mathrm{m}$. They stated that the bond among WG and cement matrix is comparable with that among quartz and cement matrix, as shown in Figure 17. Thus, the microstructure study also supports the use of finer WG as aggregate replacement. Kong et al. [107] examined the effect of WG powder on the microstructure under various curing conditions. The study demonstrates that WG powder exhibits strong pozzolanic reactions when cured in microwave or steam rather than under standard curing conditions. Matos and Sousa-Coutinho [108] conducted SEM analysis to study the microstructure of mortar containing $10 \%$ WG powder as cement replacement and compared it with the control mix as depicted in Figure 18. The glass particles appear to have been completely compressed and scattered within the hydration products of a compact, dense, and mature gel containing needle-shaped ettringite crystals (Figure 18c,d). It was seen that the $\mathrm{C}-\mathrm{S}-\mathrm{H}$ gel in samples containing WG powder has more calcium as well as more alkalis compared to the reference sample due to the pozzolanic properties of WG powder. This is the reason for having improved MPs of composites with WG powder.

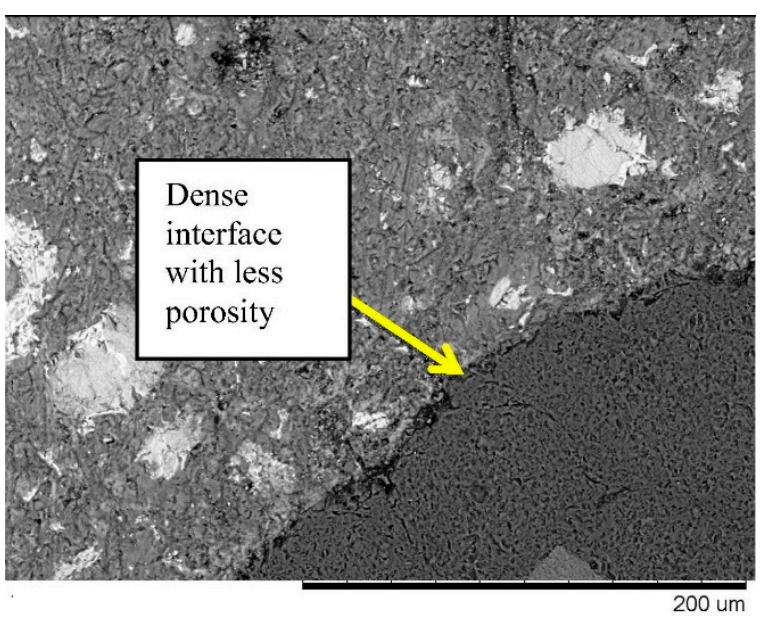

(a)

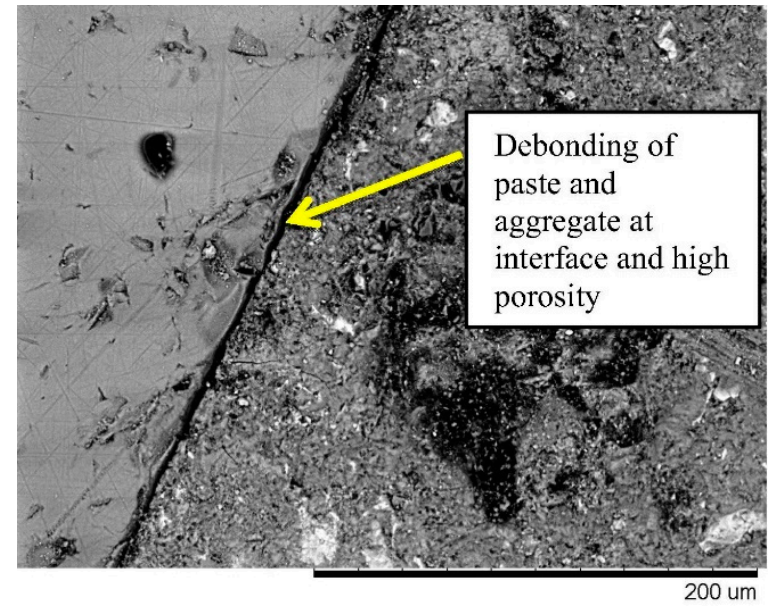

(b)

Figure 16. Microstructure of composites with: (a) natural aggregate; (b) waste glass aggregate (size: 4.75-9.5 mm) [105].

\subsection{Durability of Cement-Based Materials Containing Waste Glass}

The durability of concrete is inextricably linked to its permeability [109]. Water permeability was increased by partially replacing cement with WG. A concrete sample having a $25 \mathrm{~mm}$ penetration depth of water when $30 \%$ of the cement was substituted with

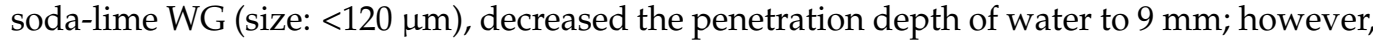
when $60 \%$ of the cement was substituted with WG, the penetration depth of water decreased it to $5 \mathrm{~mm}$ [110]. By substituting $60 \%$ natural sand for flint WG (size: $<4 \mathrm{~mm}$ ) in concrete with a $20 \mathrm{~mm}$ penetration depth of water, the penetration depth of water was decreased to $16 \mathrm{~mm}$ [111]. The use of finer WG reduced chloride penetration [79,102,112,113], while coarser WG showed less resistance to chloride penetration [114]. The percentage of water absorption reduced as the amount of WG in CBMs increased. When 20\% WG (size: $100 \mu \mathrm{m}$ ) was used in place of cement, the percentage of water absorption ratio decreased from $4.6 \%$ to $3.2 \%$ [115]. Likewise, by substituting $25 \%$ cement for WG (size: $<80 \mu \mathrm{m}$ ), the percentage 
water absorption was decreased from $6.2 \%$ to $3.8 \%$ [116]. When CRT WG (size: $<5 \mathrm{~mm}$ ) was used as sand substitute at $0 \%, 50 \%$, and $100 \%$ the water absorption ratios were $7.3 \%, 7.0 \%$, and $6.4 \%$, respectively [96]. To replace coarse aggregate, WG (size: 3-16 mm) was used, and the percentage of water absorption decreased from $6.0 \%$ to $2.5 \%$ as the proportion of WG increased from 0 to $75 \%$. Hence, consistent results revealed that proper usage of WG contributes to the reduction of CBMs' permeability and the impediment of detrimental elements transport in CBM. This enhancement is a result of the synergy of several effects, including the pozzolanic and filler effects that enhance the hydration process and improve the microstructure, thereby decreasing permeability. Simultaneously, appropriate glass gradation can increase the packing density of particles, thereby lowering the permeability even further.

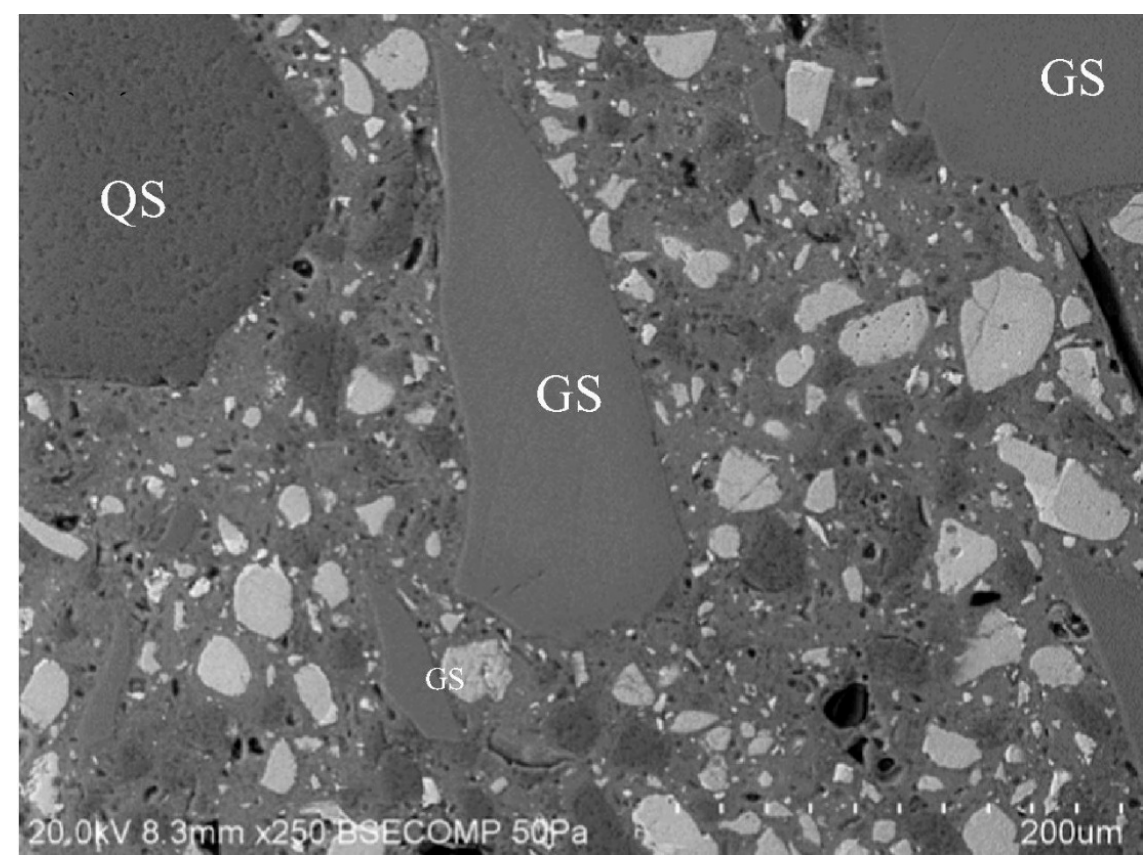

Figure 17. Microstructure of composite containing quartz and glass sand (glass mean particle size $=275 \mu \mathrm{m}$ ) [106].

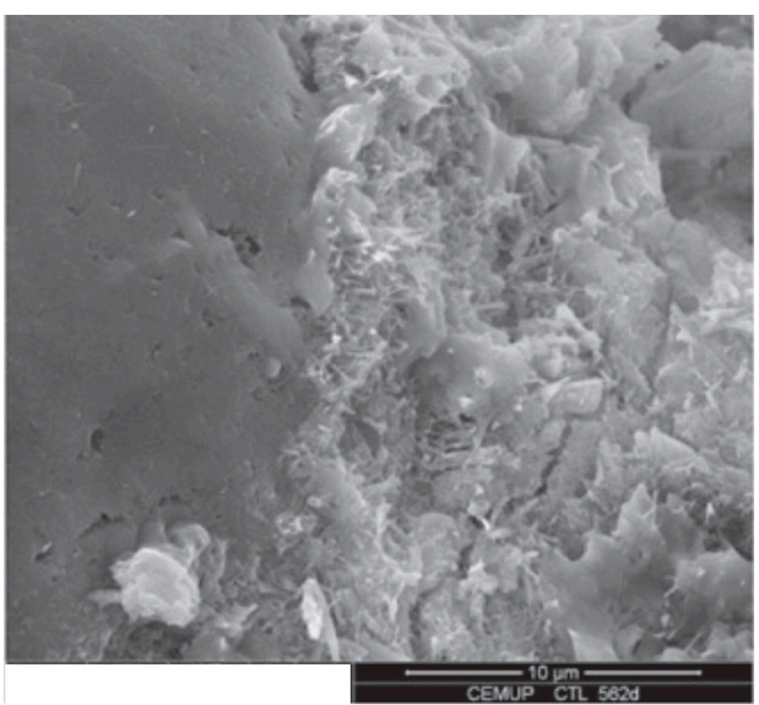

(a)

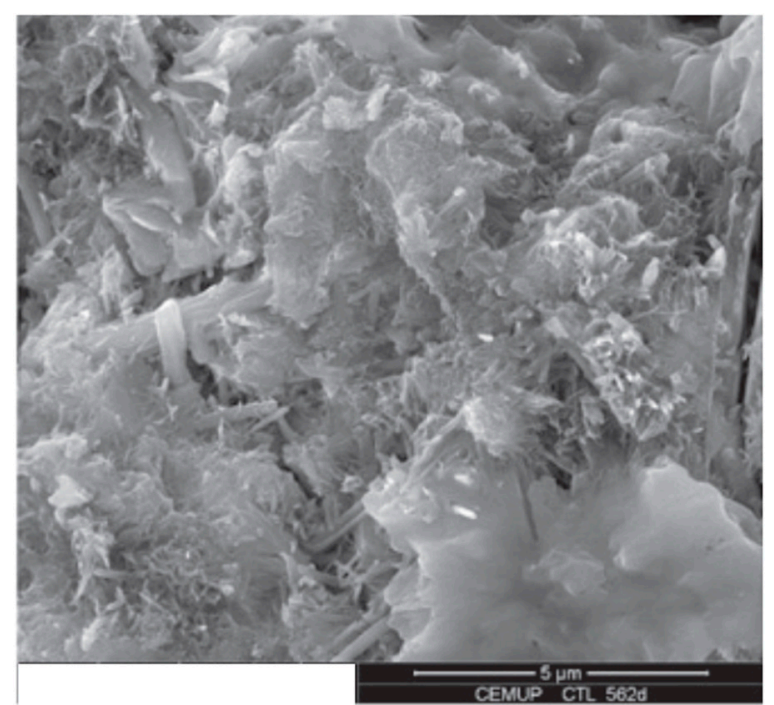

(b)

Figure 18. Cont. 


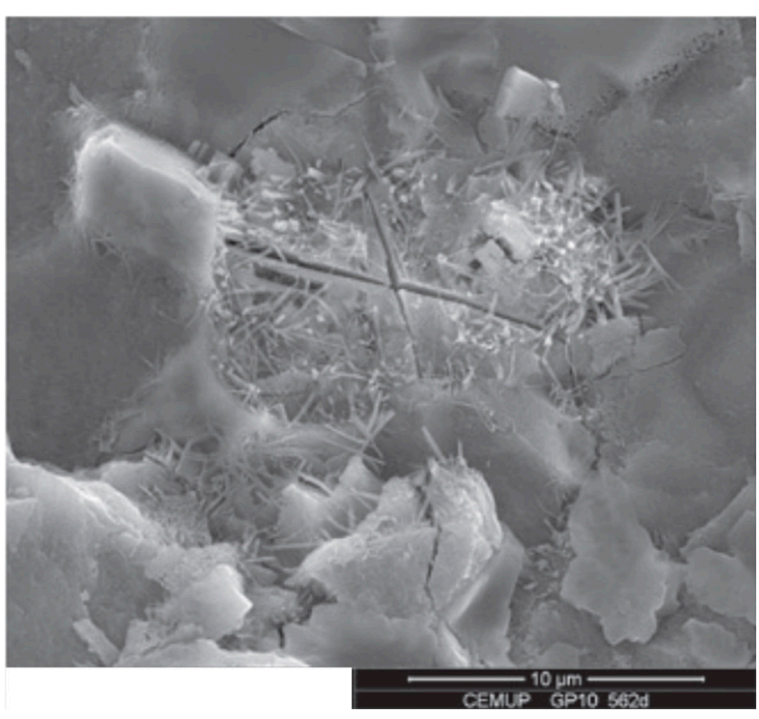

(c)

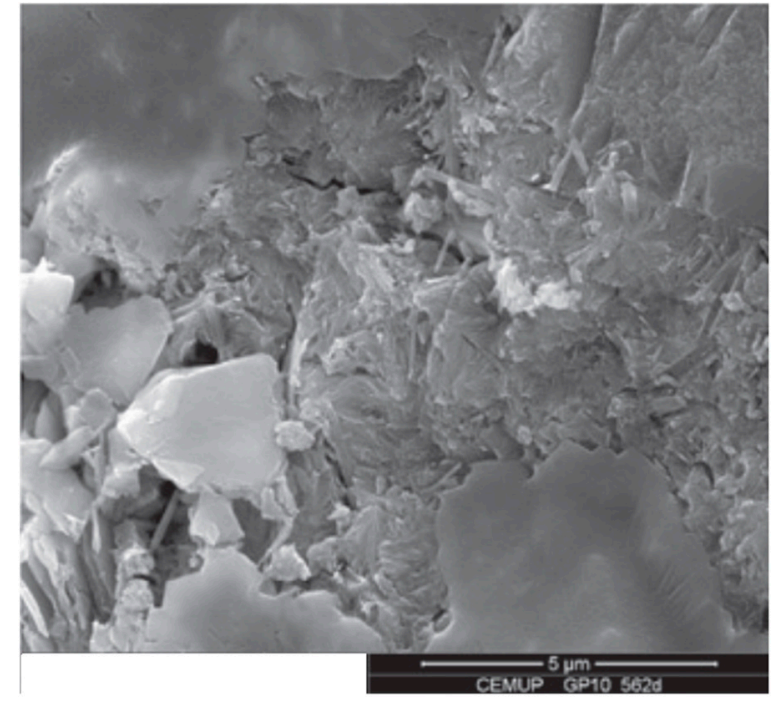

(d)

Figure 18. Microstructure of composites: (a) control mix, 10,000 times enlarged; (b) control mix, 20,000 times enlarged; (c) containing 10\% waste glass powder, 10,000 times enlarged; (d) containing 10\% waste glass powder, 20,000 times enlarged [108].

The sulphate immersion test was used to observe the resistance of CBM to sulphate attack. After five wet/dry cycles, the mass loss of concrete was determined. The mass loss was measured to be $0.8 \%$ for concrete with a $\mathrm{w} / \mathrm{b}$ of 0.68 ; however, when $40 \%$ cement in concrete was replaced by WG (size: $<150 \mu \mathrm{m}$ ), the loss in mass was decreased to $0.2 \%$ [81]. The anti-sulfate attack test revealed a consistent beneficial phenomenon. A WG (size: $<4.75 \mathrm{~mm}$ ) was used in place of natural sand in concrete, having a w/b ratio of 0.55 . With increasing proportion of WG from $0 \%$ to $80 \%$, the concrete's five-cycle mass loss decreased from $11 \%$ to $4 \%$ [117]. This increase in resistance to sulphate attack can be attributed to the concrete's refined microstructure, resulting from the pozzolanic reaction and filler effect of finer WG. The sulphate ion degrades CBMs by reacting with portlandite and forming gypsum, which sequentially forms expansive ettringite, which can crack the matrix of CBM [117]. A compact and improved microstructure prevents the passage of the sulphate ion, thereby increasing the resistance to sulphate attack.

Concrete with a w/b of 0.5 and cement was replaced by WG (size: $0.1-40 \mu \mathrm{m}$ ) at $0 \%, 10 \%$, and $20 \%$, proportions used to investigate the influence of WG on the depth of carbonation. At four months, the carbonation depth increased from $3 \mathrm{~mm}$ to $8 \mathrm{~mm}$ as the proportion of WG increased from $0 \%$ to $20 \%$ [108]. Similar observations were described in [118] when CRT WG (size: $<5 \mathrm{~mm}$ ) replaced the natural sand up to $100 \%$ in the production of heavyweight barite concrete with a w/b of 0.48 . Depth of carbonation rose from $7.5 \mathrm{~mm}$ to $11.5 \mathrm{~mm}$ as the proportion of WG increased from $25 \%$ to $100 \%$. The available data indicate that the use of WG degrades carbonation resistance. This is primarily due to the fact that glass reacts with $\mathrm{Ca}(\mathrm{OH})_{2}$ contained within concrete. The $\mathrm{Ca}(\mathrm{OH})_{2}$ aids in the delay of $\mathrm{CO}_{2}$ diffusion, and glass consumption of $\mathrm{Ca}(\mathrm{OH})_{2}$ speeds up carbonation. It is important to mention here that the studies cited above were performed on standard concrete. It is reasonable to consider that the detrimental impact of WG for resistance to carbonation can be alleviated or eliminated through microstructure refinement and low porosity, as concrete's diffusivity is decreased. There are numerous ways to decrease concrete's diffusivity, including increasing the packing density, decreasing the $\mathrm{w} / \mathrm{b}$, and using fillers.

Concrete's freezing-thawing resistance was increased by partially replacing cement with WG. Cement in concrete was replaced by electric WG (size: $13 \mu \mathrm{m}$ ), and loss in mass of the sample was reduced by $30 \%$ after 310 freezing-thawing cycles [119]. Similar findings 
were published in [120,121]. Cement was replaced by WG (size: $75 \mu \mathrm{m}$ ) at proportions of $5 \%, 10 \%$, and $15 \%$. It was found that as the proportion of WG increased from $0 \%$ to $10 \%$, the loss in mass decreased monotonically, implying that the WG enhances the resistance to freezing-thawing, most possibly because of the pozzolanic reaction and filler effect. However, as the amount of WG increased from $10 \%$ to $15 \%$, the loss in mass increased because of the dilution effect [120]. The dilution effect is related to the concrete's w/b. Due to the significant increase in the $\mathrm{w} / \mathrm{b}$ caused by substituting an extreme quantity of cement with WG, the additional water raises the porosity and results in the dilution effect. Though it is envisioned that in high-performance concrete or ultra-high-performance concrete with a very low $\mathrm{w} / \mathrm{b}$, a greater amount of cement can be substituted by WG without a dilution effect.

\section{Utilization of Waste Glass Powder in 3D Printing and Geopolimerization 7.1. $3 D$ Printing}

Three-dimensional (3D) printing of CBMs, also referred to as additive manufacturing in the construction sector, is the process of combining CBM extrusion in layers with robotic motion control [122]. Interest in 3D printing technology has increased significantly over the last few decades, both in academia and industry [123]. This is largely because it eliminates the need for formwork and human interference due to automation, which significantly decreases the time required to construct a structure. Additionally, because this technology is capable of creating complex structures, it enables structural optimization [124]. Mostly, fine aggregates were used in the 3D printing of CBMs [125]. The aggregate size is constrained by the material delivery system. The most frequently used material in 3D printing is natural sand [122]. By substituting recycled WG for natural sand in the material, a new market for WG can be created while also reducing demand for natural sand, a finite resource. With the rapid growth in the popularity of 3D printing technology, the widespread use of recycled WG as a raw material for such applications has the potential to be very beneficial. As a result, the WG recycling rate can be increased, thereby reducing the need for landfill space. Ting et al. [126] evaluated the properties of natural sand and recycled WG aggregate mortar 3D printing applications. The mixes were subjected to rheological and mechanical characterizations to compare the various aggregates' effects. The rheology results demonstrated the benefit of recycling WG in CBMs for 3D printing. The fact that the fresh material has a lower plastic viscosity and dynamic yield stress show that the recycled WG mix has better flow characteristics than the natural sand mix. This was most likely due to excess water in the recycled WG mix because of the WG particles' reduced capacity of water absorption than the natural sand, as observed in another study [114]. Other possible explanations include the smooth surface of recycled WG particles related to the natural sand particles [127]. However, the CS, STS, and flexural strength of recycled WG mixes were significantly less than those of natural sand mixes. Numerous publications have attributed these findings to the low adhesive strength amongst WG particles and the surrounding matrix at ITZ [48,114].

\subsection{Geopolimerization}

Cement is the primary constituent of concrete, acting as a binder for the aggregate particles contained in any concrete mixture. However, producing cement consumes a significant amount of energy and $\mathrm{CO}_{2}$ emission. To address this issue, most studies and research have focused on developing a more environmentally friendly alternative binder. Geopolymer is a suitable alternative to ordinary concrete. Geopolymer is a novel binder that is currently being developed. This is a type of binder that was developed to replace cement in the manufacture of concrete. The objective is to develop sustainable and environmentally friendly concrete that does not contain cement as a binder. The geopolymer contains a binder that is rich in silica and alumina. WG is an amorphous material, and its chemical composition has been listed in Table 6. Recently, WG powder has been investigated as a potential source of alumina for geopolymer production [128]. 
Geopolymers derived from WG are a relatively new field of study. According to a study, WG-based geopolymer achieved comparable CS to fly ash-based geopolymer, and the mechanical properties were highly dependent on the WG particle size, curing conditions, and alkali solution concentration [128]. Novais et al. [129] conducted a study to partially replace metakaolin with WG powder in the production of geopolymer and studied its influence on the mechanical properties. The results indicated that adding $12.5 \%$ WG increased CS by nearly $46 \%$, whereas a further increase in the amount of WG has the opposite effect when compared to the pure metakaolin-based geopolymer. Additionally, the results demonstrated the enormous influence of curing conditions on the CS of geopolymers containing WG. The CS loss was reduced considerably when geopolymers with a high WG content were cured at ambient conditions rather than in sealed bags. This allows for the addition of up to $37.5 \%$ WG without compromising CS.

\section{Conclusions and Future Recommendations}

\subsection{Conclusions}

In this study, a scientometric review was performed on the utilization of waste glass (WG) in concrete for sustainable construction, along with a comprehensive discussion. Scientometric analysis was carried out to evaluate the relevant study fields, publication trend of articles, most contributing sources, keywords co-occurrence, most cited articles and authors, and active countries contributing to the field of WG utilization in concrete for sustainable construction. Moreover, the sustainable aspects of WG utilization in construction materials were reviewed, and the influence of WG on the performance of cement-based materials (CBMs) was assessed. Particularly, the effect of WG on workability, compressive strength, split-tensile strength, flexural strength, microstructure, and durability of the resulting composite was evaluated. The following conclusions have been made:

- Scientometric analysis on the available data retrieved from the Scopus database exposed that the top four fields based on the number of documents were Engineering, Environmental Science, Materials Science, and Energy, containing 26.4\%, 22.4\%,11.6\%, and $9.9 \%$ of the total documents, respectively. A slight increase in the number of publications on the utilization of WG in construction materials was observed up to 2015. However, a remarkable increase was observed in the last 5 years. The top 3 journals based on the number of documents were found to be the journal of cleaner production, construction and building materials, and resources, conservation, and recycling, containing 241, 202, and 79 documents, respectively, of the 2066 total documents. Sustainable development, recycling, construction industry, compressive strength, and sustainability were observed to be the top 5 most occurred keywords. Additionally, the connection network demonstrated that waste management and recycling have a strong link with sustainable development and may have a sizable impact on sustainability in construction. Furthermore, India, China, and United Kingdom contributed the most documents in the current study field.

- WG can be used in CBMs as aggregate replacement and cement replacement. Thus, it conserves natural resources, solves waste management problems, reduces $\mathrm{CO}_{2}$ emission by decreasing cement demand, protects the environment from toxic chemicals, and produces cost-effective composites. Therefore, the utilization of WG in construction materials is a better approach for sustainability in construction.

- The influence of WG as aggregate/cement replacement in CBMs on the mechanical properties (MPs) was found to be inconsistent. Usually, finer glass particles improved, while coarser glass particles decreased the MPs of composites. In additions, its use in higher proportions has a negative influence on the MPs of composites.

- Due to the pozzolanic reaction and filler effect of WG powder, it is possible that substituting WG for up to $25 \%$ of the cement or $20 \%$ of natural aggregate enhanced the MPs. However, using an excessive amount of WG may decrease the mechanical strength because of the dilution effect. The optimum content of WG in concrete is related to the water/binder ratio $(\mathrm{w} / \mathrm{b})$, as the $\mathrm{w} / \mathrm{b}$ affects the amount of $\mathrm{Ca}(\mathrm{OH})_{2}$ 
reacting with glass. By substituting coarser WG for natural aggregates, the mechanical strength may be reduced. The influence of WG depends on both particle size and the proportion of the replacement.

- The addition of WG can help improve the microstructure and reduce the permeability of CBMs, thereby increasing their resistance to sulphate attack and freeze-thaw and eventually enhancing the durability of composites. However, glass may impair the resistance to carbonation because of $\mathrm{Ca}(\mathrm{OH})_{2}$ consumption by glass.

Appropriate WG selection is critical to the success of applications. It is suggested that the amount, size, and type of WG used in CBMs are appropriate for achieving adequate MPs and durability, reliant on the anticipated applications.

\subsection{Future Recommendations}

This review demonstrated the importance of developing a complete knowledge of the impacts of WG on the MPs of CBMs in order to ensure the long-term viability and durability of structures. The subsequent research needs can be found as a result of the foregoing discussions:

- Further research is essential to clarify the impact of WG on the rheological properties of CBMs in terms of amount, type, particle size, and morphology of WG particles. This is an assumption, but it is possible that the rheology of the CBMs prior to incorporating WG particles influences the glass particle's role.

- There is a necessity to explore potential coupling effects between the $\mathrm{w} / \mathrm{b}$ of concrete, the size of the WG particles, and the percentage replacement. This is an assumption, but it is possible that the $\mathrm{w} / \mathrm{b}$ of CBMs and the size of the WG particles affect the optimal content of WG, resulting in a loss of mechanical strength.

- There is a dearth of comprehensive knowledge regarding the effects of WG content and particle size on the durability of CBMs at various $w / b$. This is an assumption that the $\mathrm{w} / \mathrm{b}$ has a considerable influence on the durability-related roles of WG content and particle size.

- Computer software tools s the machine learning approach and numerical modeling need to be applied to predict the various properties of CBMs containing WG.

Author Contributions: D.Q.: conceptualization, methodology, investigation, formal analysis, visualization, and writing-original draft preparation. Y.H.: conceptualization, methodology, investigation formal analysis, writing-reviewing and editing, and supervision. X.L.: supervision, resources, funding acquisition, and writing-reviewing and editing. All authors have read and agreed to the published version of the manuscript.

Funding: Jilin Provincial Department of Science and Technology Project (20180201027SF).

Institutional Review Board Statement: Not applicable.

Informed Consent Statement: Not applicable.

Data Availability Statement: Not applicable.

Acknowledgments: This work was sponsored in part by Jilin Provincial Department of Science and Technology Project (20180201027SF).

Conflicts of Interest: The authors declare no conflict of interest.

\section{References}

1. Alwan, Z.; Jones, P.; Holgate, P. Strategic sustainable development in the UK construction industry, through the framework for strategic sustainable development, using Building Information Modelling. J. Clean. Prod. 2017, 140, 349-358. [CrossRef]

2. Doan, D.T.; Ghaffarianhoseini, A.; Naismith, N.; Zhang, T.; Ghaffarianhoseini, A.; Tookey, J. A critical comparison of green building rating systems. Build. Environ. 2017, 123, 243-260. [CrossRef]

3. Hwang, B.-G.; Zhu, L.; Tan, J.S.H. Green business park project management: Barriers and solutions for sustainable development. J. Clean. Prod. 2017, 153, 209-219. [CrossRef] 
4. Escamilla, E.Z.; Habert, G.; Wohlmuth, E. When $\mathrm{CO}_{2}$ counts: Sustainability assessment of industrialized bamboo as an alternative for social housing programs in the Philippines. Build. Environ. 2016, 103, 44-53. [CrossRef]

5. Alencar, M.H.; Priori, L., Jr.; Alencar, L.H. Structuring objectives based on value-focused thinking methodology: Creating alternatives for sustainability in the built environment. J. Clean. Prod. 2017, 156, 62-73. [CrossRef]

6. Kang, S.; Zhao, Y.; Wang, W.; Zhang, T.; Chen, T.; Yi, H.; Rao, F.; Song, S. Removal of methylene blue from water with montmorillonite nanosheets/chitosan hydrogels as adsorbent. Appl. Surf. Sci. 2018, 448, 203-211. [CrossRef]

7. Wang, W.; Zhao, Y.; Bai, H.; Zhang, T.; Ibarra-Galvan, V.; Song, S. Methylene blue removal from water using the hydrogel beads of poly (vinyl alcohol)-sodium alginate-chitosan-montmorillonite. Carbohydr. Polym. 2018, 198, 518-528. [CrossRef]

8. Ren, B.; Zhao, Y.; Bai, H.; Kang, S.; Zhang, T.; Song, S. Eco-friendly geopolymer prepared from solid wastes: A critical review. Chemosphere 2020, 267, 128900. [CrossRef]

9. Smarzewski, P. Mechanical properties of ultra-high performance concrete with partial utilization of waste foundry sand. Buildings 2020, 10, 11. [CrossRef]

10. Smarzewski, P. Influence of basalt-polypropylene fibres on fracture properties of high performance concrete. Compos. Struct. 2019, 209, 23-33. [CrossRef]

11. Smarzewski, P. Influence of silica fume on mechanical and fracture properties of high performance concrete. Procedia Struct. Integr. 2019, 17, 5-12. [CrossRef]

12. Smarzewski, P. Study of Bond Strength of Steel Bars in Basalt Fibre Reinforced High Performance Concrete. Crystals 2020, 10, 436. [CrossRef]

13. Smarzewski, P. Flexural toughness of high-performance concrete with basalt and polypropylene short fibres. Adv. Civ. Eng. 2018, 2018, 5024353. [CrossRef]

14. Smarzewski, P. Comparative Fracture Properties of Four Fibre Reinforced High Performance Cementitious Composites. Materials 2020, 13, 2612. [CrossRef]

15. Ahmad, W.; Farooq, S.H.; Usman, M.; Khan, M.; Ahmad, A.; Aslam, F.; Yousef, R.A.; Abduljabbar, H.A.; Sufian, M. Effect of coconut fiber length and content on properties of high strength concrete. Materials 2020, 13, 1075. [CrossRef]

16. Smarzewski, P. Flexural toughness evaluation of basalt fibre reinforced HPC beams with and without initial notch. Compos. Struct. 2020, 235, 111769. [CrossRef]

17. Colangelo, F.; Cioffi, R.; Liguori, B.; Iucolano, F. Recycled polyolefins waste as aggregates for lightweight concrete. Compos. Part B Eng. 2016, 106, 234-241. [CrossRef]

18. Asutkar, P.; Shinde, S.; Patel, R. Study on the behaviour of rubber aggregates concrete beams using analytical approach. Eng. Sci. Technol. Int. J. 2017, 20, 151-159. [CrossRef]

19. Ferreira, L.; de Brito, J.; Saikia, N. Influence of curing conditions on the mechanical performance of concrete containing recycled plastic aggregate. Constr. Build. Mater. 2012, 36, 196-204. [CrossRef]

20. Saikia, N.; Brito, J.D. Waste polyethylene terephthalate as an aggregate in concrete. Mater. Res. 2013, 16, 341-350. [CrossRef]

21. Rashad, A.M. Recycled waste glass as fine aggregate replacement in cementitious materials based on Portland cement. Constr. Build. Mater. 2014, 72, 340-357. [CrossRef]

22. Smarzewski, P.; Barnat-Hunek, D. Mechanical and durability related properties of high performance concrete made with coal cinder and waste foundry sand. Constr. Build. Mater. 2016, 121, 9-17. [CrossRef]

23. Arshad, S.; Sharif, M.B.; Irfan-ul-Hassan, M.; Khan, M.; Zhang, J.-L. Efficiency of Supplementary Cementitious Materials and Natural Fiber on Mechanical Performance of Concrete. Arab. J. Sci. Eng. 2020, 45, 8577-8589. [CrossRef]

24. Khan, M.; Ali, M. Effect of super plasticizer on the properties of medium strength concrete prepared with coconut fiber. Constr. Build. Mater. 2018, 182, 703-715. [CrossRef]

25. Khan, M.; Rehman, A.; Ali, M. Efficiency of silica-fume content in plain and natural fiber reinforced concrete for concrete road. Constr. Build. Mater. 2020, 244, 118382. [CrossRef]

26. Khan, U.A.; Jahanzaib, H.M.; Khan, M.; Ali, M. Improving the Tensile Energy Absorption of High Strength Natural Fiber Reinforced Concrete with Fly-Ash for Bridge Girders, Key Engineering Materials; Trans Tech Publications: Stafa-Zurich, Switzerland, 2018; Volume 765, pp. 335-342.

27. Pelisser, F.; Montedo, O.R.K.; Gleize, P.J.P.; Roman, H.R. Mechanical properties of recycled PET fibers in concrete. Mater. Res. 2012, 15, 679-686. [CrossRef]

28. Merli, R.; Preziosi, M.; Acampora, A.; Lucchetti, M.C.; Petrucci, E. Recycled fibers in reinforced concrete: A systematic literature review. J. Clean. Prod. 2020, 248, 119207. [CrossRef]

29. Liu, J.; Liu, J.; Huang, Z.; Zhu, J.; Liu, W.; Zhang, W. Effect of Fly Ash as Cement Replacement on Chloride Diffusion, Chloride Binding Capacity, and Micro-Properties of Concrete in a Water Soaking Environment. Appl. Sci. 2020, 10, 6271. [CrossRef]

30. Bueno, E.T.; Paris, J.M.; Clavier, K.A.; Spreadbury, C.; Ferraro, C.C.; Townsend, T.G. A review of ground waste glass as a supplementary cementitious material: A focus on alkali-silica reaction. J. Clean. Prod. 2020, 257, 120180. [CrossRef]

31. Hamada, H.M.; Thomas, B.S.; Yahaya, F.M.; Muthusamy, K.; Yang, J.; Abdalla, J.A.; Hawileh, R.A. Sustainable use of palm oil fuel ash as a supplementary cementitious material: A comprehensive review. J. Build. Eng. 2021, 40, 102286. [CrossRef]

32. Chore, H.S.; Joshi, M.P. Strength characterization of concrete using industrial waste as cement replacing materials for rigid pavement. Innov. Infrastruct. Solut. 2020, 5, 1-9. [CrossRef] 
33. Lim, N.H.A.S.; Shaari, F.H.; Shaari, E.H.; Sam, A.R.M.; Khalid, N.H.A.; Ariffin, N.F.; Muthusamy, K. Properties of Concrete Containing Bamboo Waste as Cement Replacement. J. Comput. Theor. Nanosci. 2020, 17, 1306-1310.

34. Rattanachu, P.; Toolkasikorn, P.; Tangchirapat, W.; Chindaprasirt, P.; Jaturapitakkul, C. Performance of recycled aggregate concrete with rice husk ash as cement binder. Cem. Concr. Compos. 2020, 108, 103533. [CrossRef]

35. Khan, M.; Ali, M. Improvement in concrete behavior with fly ash, silica-fume and coconut fibres. Constr. Build. Mater. 2019, 203, 174-187. [CrossRef]

36. Saikia, N.; De Brito, J. Use of plastic waste as aggregate in cement mortar and concrete preparation: A review. Constr. Build. Mater. 2012, 34, 385-401. [CrossRef]

37. Jain, K.L.; Sancheti, G.; Gupta, L.K. Durability performance of waste granite and glass powder added concrete. Constr. Build. Mater. 2020, 252, 119075. [CrossRef]

38. Martínez-Barrera, G.; del Coz-Díaz, J.J.; Álvarez-Rabanal, F.P.; Gayarre, F.L.; Martínez-López, M.; Cruz-Olivares, J. Waste tire rubber particles modified by gamma radiation and their use as modifiers of concrete. Case Stud. Constr. Mater. 2020, 12 , e00321. [CrossRef]

39. Topcu, I.B.; Canbaz, M. Properties of concrete containing waste glass. Cem. Concr. Res. 2004, 34, 267-274. [CrossRef]

40. Meena, A.; Singh, R. Comparative Study of Waste Glass Powder as Pozzolanic Material in Concrete; Department of Civil Engineering, National Institute of Technology: Rourkela, India, 2012.

41. Pant, D.; Singh, P. Pollution due to hazardous glass waste. Environ. Sci. Pollut. Res. 2014, 21, 2414-2436. [CrossRef] [PubMed]

42. Singh, N.; Li, J.; Zeng, X. Solutions and challenges in recycling waste cathode-ray tubes. J. Clean. Prod. 2016, 133, 188-200. [CrossRef]

43. Olofinnade, O.M.; Ndambuki, J.M.; Ede, A.N.; Booth, C. Application of waste glass powder as a partial cement substitute towards more sustainable concrete production. Int. J. Eng. Res. Africa. 2017, 31, 77-93. [CrossRef]

44. Shelby, J. Introduction to Glass Science and Technology; The Royal Society of Chemistry: Cambridge, UK, 2005.

45. Schmitz, A.; Kamiński, J.; Scalet, B.M.; Soria, A. Energy consumption and $\mathrm{CO}_{2}$ emissions of the European glass industry. Energy Policy 2011, 39, 142-155. [CrossRef]

46. Jani, Y.; Hogland, W. Waste glass in the production of cement and concrete-A review. J. Environ. Chem. Eng. 2014, 2, 1767-1775. [CrossRef]

47. Federico, L.; Chidiac, S. Waste glass as a supplementary cementitious material in concrete-critical review of treatment methods. Cem. Concr. Compos. 2009, 31, 606-610. [CrossRef]

48. Mohajerani, A.; Vajna, J.; Cheung, T.H.H.; Kurmus, H.; Arulrajah, A.; Horpibulsuk, S. Practical recycling applications of crushed waste glass in construction materials: A review. Constr. Build. Mater. 2017, 156, 443-467. [CrossRef]

49. Rashad, A.M. Recycled cathode ray tube and liquid crystal display glass as fine aggregate replacement in cementitious materials. Constr. Build. Mater. 2015, 93, 1236-1248. [CrossRef]

50. Paul, S.C.; Šavija, B.; Babafemi, A.J. A comprehensive review on mechanical and durability properties of cement-based materials containing waste recycled glass. J. Clean. Prod. 2018, 198, 891-906. [CrossRef]

51. Aliabdo, A.A.; Elmoaty, M.A.; Aboshama, A.Y. Utilization of waste glass powder in the production of cement and concrete. Constr. Build. Mater. 2016, 124, 866-877. [CrossRef]

52. Xu, Y.; Zeng, J.; Chen, W.; Jin, R.; Li, B.; Pan, Z. A holistic review of cement composites reinforced with graphene oxide. Constr. Build. Mater. 2018, 171, 291-302. [CrossRef]

53. Xiao, X.; Skitmore, M.; Li, H.; Xia, B. Mapping knowledge in the economic areas of green building using scientometric analysis. Energies 2019, 12, 3011. [CrossRef]

54. Mryglod, O.; Holovatch, Y.; Kenna, R. Data mining in scientometrics: Usage analysis for academic publications. In Proceedings of the 2018 IEEE Second International Conference on Data Stream Mining \& Processing (DSMP), Lviv, Ukraine, 21-25 August 2018; IEEE: Piscataway, NJ, USA, 2018; pp. 241-246.

55. Darko, A.; Chan, A.P.; Huo, X.; Owusu-Manu, D.-G. A scientometric analysis and visualization of global green building research. Build. Environ. 2019, 149, 501-511. [CrossRef]

56. Song, J.; Zhang, H.; Dong, W. A review of emerging trends in global PPP research: Analysis and visualization. Scientometrics 2016, 107, 1111-1147. [CrossRef]

57. Hosseini, M.R.; Martek, I.; Zavadskas, E.K.; Aibinu, A.A.; Arashpour, M.; Chileshe, N. Critical evaluation of off-site construction research: A Scientometric analysis. Autom. Constr. 2018, 87, 235-247. [CrossRef]

58. Liao, H.; Tang, M.; Luo, L.; Li, C.; Chiclana, F.; Zeng, X.-J. A bibliometric analysis and visualization of medical big data research. Sustainability 2018, 10, 166. [CrossRef]

59. Chadegani, A.A.; Salehi, H.; Yunus, M.; Farhadi, H.; Fooladi, M.; Farhadi, M.; Ebrahim, N.A. A comparison between two main academic literature collections: Web of Science and Scopus databases. Asian Soc. Sci. 2013, 9, 18-26. [CrossRef]

60. Bergman, E.M.L. Finding citations to social work literature: The relative benefits of using Web of Science, Scopus, or Google Scholar. J. Acad. Librariansh. 2012, 38, 370-379. [CrossRef]

61. Meho, L.I. Using Scopus's CiteScore for assessing the quality of computer science conferences. J. Informetr. 2019, 13, 419-433. [CrossRef]

62. Zuo, J.; Zhao, Z.-Y. Green building research-current status and future agenda: A review. Renew. Sustain. Energy Rev. 2014, 30, 271-281. [CrossRef] 
63. Darko, A.; Zhang, C.; Chan, A.P. Drivers for green building: A review of empirical studies. Habitat Int. 2017, 60, 34-49. [CrossRef]

64. Ahmad, W.; Khan, M.; Smarzewski, P. Effect of Short Fiber Reinforcements on Fracture Performance of Cement-Based Materials: A Systematic Review Approach. Materials 2021, 14, 1745. [CrossRef] [PubMed]

65. Markoulli, M.P.; Lee, C.I.; Byington, E.; Felps, W.A. Mapping Human Resource Management: Reviewing the field and charting future directions. Hum. Resour. Manag. Rev. 2017, 27, 367-396. [CrossRef]

66. Saka, A.B.; Chan, D.W. A scientometric review and metasynthesis of building information modelling (BIM) research in Africa. Buildings 2019, 9, 85. [CrossRef]

67. Goulden, S.; Erell, E.; Garb, Y.; Pearlmutter, D. Green building standards as socio-technical actors in municipal environmental policy. Build. Res. Inf. 2017, 45, 414-425. [CrossRef]

68. Jin, R.; Gao, S.; Cheshmehzangi, A.; Aboagye-Nimo, E. A holistic review of off-site construction literature published between 2008 and 2018. J. Clean. Prod. 2018, 202, 1202-1219. [CrossRef]

69. Park, J.Y.; Nagy, Z. Comprehensive analysis of the relationship between thermal comfort and building control research-A data-driven literature review. Renew. Sustain. Energy Rev. 2018, 82, 2664-2679. [CrossRef]

70. Oraee, M.; Hosseini, M.R.; Papadonikolaki, E.; Palliyaguru, R.; Arashpour, M. Collaboration in BIM-based construction networks: A bibliometric-qualitative literature review. Int. J. Proj. Manag. 2017, 35, 1288-1301. [CrossRef]

71. Van Eck, N.J.; Waltman, L. Software survey: VOSviewer, a computer program for bibliometric mapping. Scientometrics 2010, 84, 523-538. [CrossRef]

72. Wuni, I.Y.; Shen, G.Q.; Osei-Kyei, R. Scientometric review of global research trends on green buildings in construction journals from 1992 to 2018. Energy Build. 2019, 190, 69-85. [CrossRef]

73. Su, H.-N.; Lee, P.-C. Mapping knowledge structure by keyword co-occurrence: A first look at journal papers in Technology Foresight. Scientometrics 2010, 85, 65-79. [CrossRef]

74. Yu, F.; Hayes, B.E. Applying data analytics and visualization to assessing the research impact of the Cancer Cell Biology (CCB) Program at the University of North Carolina at Chapel Hill. J. Sci. Librariansh. 2018, 7, 4. [CrossRef]

75. Meyer, C. The greening of the concrete industry. Cem. Concr. Compos. 2009, 31, 601-605. [CrossRef]

76. Shayan, A.; Xu, A. Value-added utilisation of waste glass in concrete. Cem. Concr. Res. 2004, 34, 81-89. [CrossRef]

77. Vieitez, E.R.; Eder, P.; Villanueva, A.; Saveyn, H. End-of-Waste Criteria for Glass Cullet: Technical Proposals; JRC Scientific and Technical Reports; Publications Office of the European Union: Mercier, Luxembourg, 2011.

78. Jin, W.; Meyer, C.; Baxter, S. Glascrete-Concrete with glass aggregate. ACI Mater. J. 2000, 97, 208-213.

79. Elaqra, H.A.; Haloub, M.A.A.; Rustom, R.N. Effect of new mixing method of glass powder as cement replacement on mechanical behavior of concrete. Constr. Build. Mater. 2019, 203, 75-82. [CrossRef]

80. Chen, C.; Huang, R.; Wu, J.; Yang, C.-C. Waste E-glass particles used in cementitious mixtures. Cem. Concr. Res. 2006, 36, 449-456. [CrossRef]

81. Kou, S.; Poon, C.S. Properties of self-compacting concrete prepared with recycled glass aggregate. Cem. Concr. Compos. 2009, 31, 107-113. [CrossRef]

82. Rehman, S.; Iqbal, S.; Ali, A. Combined influence of glass powder and granular steel slag on fresh and mechanical properties of self-compacting concrete. Constr. Build. Mater. 2018, 178, 153-160. [CrossRef]

83. Hendi, A.; Mostofinejad, D.; Sedaghatdoost, A.; Zohrabi, M.; Naeimi, N.; Tavakolinia, A. Mix design of the green self-consolidating concrete: Incorporating the waste glass powder. Constr. Build. Mater. 2019, 199, 369-384. [CrossRef]

84. Wang, H.-Y.; Huang, W.-L. A study on the properties of fresh self-consolidating glass concrete (SCGC). Constr. Build. Mater. 2010, 24, 619-624. [CrossRef]

85. Tuaum, A.; Shitote, S.; Oyawa, W. Experimental study of self-compacting mortar incorporating recycled glass aggregate. Buildings 2018, 8, 15. [CrossRef]

86. Taha, B.; Nounu, G. Utilizing waste recycled glass as sand/cement replacement in concrete. J. Mater. Civ. Eng. 2009, 21, 709-721. [CrossRef]

87. Liu, H.; Shi, J.; Qu, H.; Ding, D. An investigation on physical, mechanical, leaching and radiation shielding behaviors of barite concrete containing recycled cathode ray tube funnel glass aggregate. Constr. Build. Mater. 2019, 201, 818-827. [CrossRef]

88. Wang, H.-Y.; Huang, W.-L. Durability of self-consolidating concrete using waste LCD glass. Constr. Build. Mater. 2010, 24, 1008-1013. [CrossRef]

89. Gorospe, K.; Booya, E.; Ghaednia, H.; Das, S.J.C.; Materials, B. Effect of various glass aggregates on the shrinkage and expansion of cement mortar. Constr. Build. Mater. 2019, 210, 301-311. [CrossRef]

90. Song, W.; Zou, D.; Liu, T.; Teng, J.; Li, L. Effects of recycled CRT glass fine aggregate size and content on mechanical and damping properties of concrete. Constr. Build. Mater. 2019, 202, 332-340. [CrossRef]

91. Ismail, Z.Z.; Al-Hashmi, E.A. Recycling of waste glass as a partial replacement for fine aggregate in concrete. Waste Manag. 2009, 29, 655-659. [CrossRef]

92. Abdallah, S.; Fan, M. Characteristics of concrete with waste glass as fine aggregate replacement. Int. J. Eng. Tech. Res. 2014, 2, 11-17.

93. Malik, M.I.; Bashir, M.; Ahmad, S.; Tariq, T.; Chowdhary, U. Study of concrete involving use of waste glass as partial replacement of fine aggregates. IOSR J. Eng. 2013, 3, 8-13. [CrossRef] 
94. Olofinnade, O.M.; Ndambuki, J.M.; Ede, A.N.; Olukanni, D.O. Effect of substitution of crushed waste glass as partial replacement for natural fine and coarse aggregate in concrete. Mater. Sci. Forum 2016, 866, 58-62. [CrossRef]

95. Małek, M.; Łasica, W.; Jackowski, M.; Kadela, M. Effect of waste glass addition as a replacement for fine aggregate on properties of mortar. Materials 2020, 13, 3189. [CrossRef]

96. Kim, I.S.; Choi, S.Y.; Yang, E.I. Evaluation of durability of concrete substituted heavyweight waste glass as fine aggregate. Constr. Build. Mater. 2018, 184, 269-277. [CrossRef]

97. Sikora, P.; Augustyniak, A.; Cendrowski, K.; Horszczaruk, E.; Rucinska, T.; Nawrotek, P.; Mijowska, E. Characterization of mechanical and bactericidal properties of cement mortars containing waste glass aggregate and nanomaterials. Materials 2016, 9, 701. [CrossRef] [PubMed]

98. Islam, G.S.; Rahman, M.; Kazi, N. Waste glass powder as partial replacement of cement for sustainable concrete practice. Int. J. Sustain. Built Environ. 2017, 6, 37-44. [CrossRef]

99. Soliman, N.; Tagnit-Hamou, A. Partial substitution of silica fume with fine glass powder in UHPC: Filling the micro gap. Constr. Build. Mater. 2017, 139, 374-383. [CrossRef]

100. L-Zubaid, A.B.A.; Shabeeb, K.M.; Ali, A.I. Study the effect of recycled glass on the mechanical properties of green concrete. Energy Procedia 2017, 119, 680-692. [CrossRef]

101. Anwar, A. The influence of waste glass powder as a pozzolanic material in concrete. Int. J. Civ. Eng. Technol 2016, 7, 131-148.

102. Kamali, M.; Ghahremaninezhad, A. Effect of glass powders on the mechanical and durability properties of cementitious materials. Constr. Build. Mater. 2015, 98, 407-416. [CrossRef]

103. Hama, S.M. Improving mechanical properties of lightweight Porcelanite aggregate concrete using different waste material. Int. J. Sustain. Built Environ. 2017, 6, 81-90. [CrossRef]

104. Olutoge, F. Effect of waste glass powder (WGP) on the mechanical properties of concrete. Am. J. Eng. Res. 2016, 5, 213-220.

105. Afshinnia, K.; Rangaraju, P.R. Impact of combined use of ground glass powder and crushed glass aggregate on selected properties of Portland cement concrete. Constr. Build. Mater. 2016, 117, 263-272. [CrossRef]

106. Soliman, N.A.; Tagnit-Hamou, A. Using glass sand as an alternative for quartz sand in UHPC. Constr. Build. Mater. 2017, 145, 243-252. [CrossRef]

107. Kong, Y.; Wang, P.; Liu, S.; Gao, Z.; Rao, M. Effect of microwave curing on the hydration properties of cement-based material containing glass powder. Constr. Build. Mater. 2018, 158, 563-573. [CrossRef]

108. Matos, A.M.; Sousa-Coutinho, J. Durability of mortar using waste glass powder as cement replacement. Constr. Build. Mater. 2012, 36, 205-215. [CrossRef]

109. Tony, S.; Ion, D.; Bob, B. Long Term Durability Properties of Field Concretes with Glass Sand and Glass Powder. In Proceedings of the Fourth International Conference on Sustainable Construction Materials and Technologies, Las Vegas, NV, USA, 7-11 August 2016.

110. Du, H.; Tan, K. Durability performance of concrete with glass powder as supplementary cementitious material. ACI Mater. J. 2015, 112, 429-438.

111. Mardani-Aghabaglou, A.; Tuyan, M.; Ramyar, K. Mechanical and durability performance of concrete incorporating fine recycled concrete and glass aggregates. Mater. Struct. 2015, 48, 2629-2640. [CrossRef]

112. Patel, D.; Shrivastava, R.; Tiwari, R.; Yadav, R. Properties of cement mortar in substitution with waste fine glass powder and environmental impact study. J. Build. Eng. 2020, 27, 100940. [CrossRef]

113. Lalitha, G.; Sasidhar, C.; Ramachandrudu, C. Durability performance of concrete (M-60) fine aggregate partially replaced with crushed waste glass. Technology 2020, 11, 1-9.

114. Tan, K.H.; Du, H. Use of waste glass as sand in mortar: Part I-Fresh, mechanical and durability properties. Cem. Concr. Compos. 2013, 35, 109-117. [CrossRef]

115. Patel, D.; Tiwari, R.; Shrivastava, R.; Yadav, R. Effective utilization of waste glass powder as the substitution of cement in making paste and mortar. Constr. Build. Mater. 2019, 199, 406-415. [CrossRef]

116. Disfani, M.; Arulrajah, A.; Bo, M.; Sivakugan, N. Environmental risks of using recycled crushed glass in road applications. J. Clean. Prod. 2012, 20, 170-179. [CrossRef]

117. Wang, H.-Y. A study of the effects of LCD glass sand on the properties of concrete. Waste Manag. 2009, 29, 335-341. [CrossRef]

118. Ling, T.-C.; Poon, C.-S. Feasible use of recycled CRT funnel glass as heavyweight fine aggregate in barite concrete. J. Clean. Prod. 2012, 33, 42-49. [CrossRef]

119. Soroushian, P. Strength and durability of recycled aggregate concrete containing milled glass as partial replacement for cement. Constr. Build. Mater. 2012, 29, 368-377.

120. Abendeh, R.; Baker, M.B.; Salem, Z.A.; Ahmad, H. The feasibility of using milled glass wastes in concrete to resist freezing-thawing action. Int. J. Civ. Environ. Eng. 2015, 9, 1026-1029.

121. Al-Akhras, N.M. Performance of glass concrete subjected to freeze-thaw cycling. Constr. Build. Technol. J. 2012, 6, 392-397. [CrossRef]

122. Tay, Y.W.D.; Ting, G.H.A.; Qian, Y.; Panda, B.; He, L.; Tan, M.J. Time gap effect on bond strength of 3D-printed concrete. Virtual Phys. Prototyp. 2019, 14, 104-113. [CrossRef]

123. Tay, Y.W.D.; Panda, B.; Paul, S.C.; Noor Mohamed, N.A.; Tan, M.J.; Leong, K.F. 3D printing trends in building and construction industry: A review. Virtual Phys. Prototyp. 2017, 12, 261-276. [CrossRef] 
124. Bos, F.; Wolfs, R.; Ahmed, Z.; Salet, T. Additive manufacturing of concrete in construction: Potentials and challenges of 3D concrete printing. Virtual Phys. Prototyp. 2016, 11, 209-225. [CrossRef]

125. Gosselin, C.; Duballet, R.; Roux, P.; Gaudillière, N.; Dirrenberger, J.; Morel, P. Large-scale 3D printing of ultra-high performance concrete-A new processing route for architects and builders. Mater. Des. 2016, 100, 102-109. [CrossRef]

126. Ting, G.H.A.; Tay, Y.W.D.; Qian, Y.; Tan, M.J. Utilization of recycled glass for 3D concrete printing: Rheological and mechanical properties. J. Mater. Cycles Waste Manag. 2019, 21, 994-1003. [CrossRef]

127. Jiao, D.; Shi, C.; Yuan, Q.; An, X.; Liu, Y.; Li, H. Effect of constituents on rheological properties of fresh concrete-A review. Cem. Concr. Compos. 2017, 83, 146-159. [CrossRef]

128. Cyr, M.; Idir, R.; Poinot, T. Properties of inorganic polymer (geopolymer) mortars made of glass cullet. J. Mater. Sci. 2012, 47, 2782-2797. [CrossRef]

129. Novais, R.M.; Ascensão, G.; Seabra, M.; Labrincha, J. Waste glass from end-of-life fluorescent lamps as raw material in geopolymers. Waste Manag. 2016, 52, 245-255. [CrossRef] 